\title{
NBSIR 77-1312
}

\section{Physical Properties of Smokes Pertinent to Smoke Detector Technology}

Thomas G. K. Lee and George Mulholland

Center for Fire Research

Institute for Applied Technology

National Bureau of Standards

Washington, D.C. 20234

November 1977

Final Report

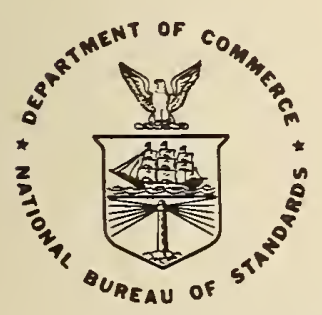

U.S. DEPARTMENT OF COMMERCE

NATIONAL BUREAU OF STANDARDS 

NBSIR 77-1312

\section{PHYSICAL PROPERTIES OF SMOKES \\ PERTINENT TO SMOKE DETECTOR TECHNOLOGY}

Thomas G. K. Lee and George Mulholland

Center for Fire Research

Institute for Applied Technology

National Bureau of Standards

Washington, D.C. 20234

November 1977

Final Report

U.S. DEPARTMENT OF COMMERCE, Juanita M. Kreps, Secretary

Dr. Sidney Harman, Under Secretary

Jordan J. Baruch, Assistant Secretary for Science and Technology

NATIONAL BUREAU OF STANDARDS, Ernest Ambler, Acting Director 



\section{CONTENTS}

Page

LIST OF FIGURES . . . . . . . . . . . . . . . . . . . . . . . . . . . . . iv

LIST OF TABLES . . . . . . . . . . . . . . . . . . . . . . . . . . . . IV

Abstract . . . . . . . . . . . . . . . . . . . . . . . . . . . 1

1. INTRODUCTION . . . . . . . . . . . . . . . . . . . . . . . . 1

2. FIRE SMOKE PROPERTIES . . . . . . . . . . . . . . . . . . . . . . . . 3

2.1. Definition of Fire Smoke . . . . . . . . . . . . . . . . . . . . 3

2.2. Particle Size and Its Distribution . . . . . . . . . . . . . . . 5

2.3. Number Concentration and Mass Concentration . . . . . . . . . . . . 8

3. MEASUREMENT METHODS . . . . . . . . . . . . . . . . . . . . . . . 8

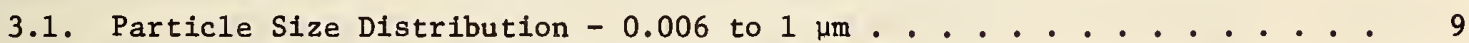

3.2. Particle Size Distribution 0.5 to $5 \mu$. . . . . . . . . . . . . . . 11

3.3. Number Concentration 300 to $10^{7} \mathrm{~cm}^{-3}$. . . . . . . . . . . . . . 12

3.4. Mass Concentration . . . . . . . . . . . . . . . . . . . 13

3.5. Aerosol Chamber . . . . . . . . . . . . . . . . . . . . 14

3.6. UL 217 Smoke Detector Evaluation Chamber . . . . . . . . . . . . . . 15

4. AEROSOL SOURCE MATERIALS AND DILUTION . . . . . . . . . . . . . . . . . 17

4.1. Method for Aerosol Dilution . . . . . . . . . . . . . . . . . 19

5. RESULTS • . . . . . . . . . . . . . . . . . . . . . . . 19

5.1. Smokes in the UL 217 Chamber . . . . . . . . . . . . . . . . . . . 19

5.2. The Effect of Pyrolysis Conditions on Particle Sizes . . . . . . . . . . 27

5.3. Effect of Flaming and Non-flaming Exposure on Particle Size of $\alpha$-cellulose Smoke . . . . . . . . . . . . . . . . . . . 27

5.4. Influence of Pyrolysis Air Temperature . . . . . . . . . . . . . . . . 30

5.5. Influence of Aging on Particle Size Distribution . . . . . . . . . . . 30

6. DISCUSSION . . . . . . . . . . . . . . . . . . . . . . . 33

6.1. Comparison of Measurement Methods . . . . . . . . . . . . . . . . 33

6.2. UL 217 Detector Evaluation Chamber . . . . . . . . . . . . . . . . 34

6.3. Aerosol Generation Modes . . . . . . . . . . . . . . . . . . . 34

6.4. Aerosol Aging and Coagulation Losses... . . . . . . . . . . . . . . 34

6.5. Universal Size Distribution . . . . . . . . . . . . . . . . 35

7. SUMMARY AND CONCLUSIONS . . . . . . . . . . . . . . . . . . . . . 38

8. REFERENCES . . . . . . . . . . . . . . . . . . . . . . . . 40 
Figure 1. Detector sensitivity for two types of detectors exposed to monodisperse aerosols . . . . . . . . . . . . . . . . . . . . 4

Figure 2. Discrete size ranges of the Electrical Aerosol Analyzer . . . . . . . 6

Figure 3. Smoke detector evaluation chamber from UL 217 . . . . . . . . . . . 16

Figure 4. Aerosol diluter, dilution factor depends on orifice sizes . . . . . . 18

Figure 5. Size distribution of an aerosol before and after dilution . . . . . . 20

Figure 6. Mass concentration versus smoke obscuration in UL 217 . . . . . . . . 22

Figure 7. Number concentration versus smoke obscuration in UL $217 .$. . . . . . 23

Figure 8. Particle size distribution for lamp wick and heptane smokes . . . . . 25

Figure 9. Effect of air movement $(2 \mathrm{~m} / \mathrm{s})$ on particle size . . . . . . . . . 26

Figure 10. Smoke from $\alpha$-cellulose under flaming and non-flaming exposure conditions . . . . . . . . . . . . . . . . . . . . . . 28

Figure 11. Aging of aerosol from source which progress from smoldering to flaming . . . . . . . . . . . . . . . . . . . . . 29

Figure 12. Aging of aerosols generated at two temperatures . . . . . . . . . . . 31

Figure 13. Aging of punk aerosol up to 16 hours . . . . . . . . . . . . . . 32

Figure 14. Representative size distributions in terms of reduced variables . . . . 36

\author{
LIST OF TABLES
}

Page

Table 1. Performance of Instruments . . . . . . . . . . . . . . . . . . . 10

Table 2. Measured and Derived Parameters of Smokes in the UL 217

Chamber Test . . . . . . . . . . . . . . . . . . . . . . 


\section{PHYSICAL PROPERTIES OF SMOKES PERTINENT \\ TO SMOKE DETECTOR TECHNOLOGY}

Thomas G. K. Lee and George Mulholland

\section{Abstract}

Several commercially available aerosol instruments including the electrical aerosol analyzer, nuclei condensation monitor, quartz mass monitor, and optical particle counter were used to measure particle size distribution of smokes from burning heptane and cellulosic materials. Some limitations of these instruments are discussed. Parameters such as mode of exposure (flaming versus smoldering), pyrolysis temperature, air velocity at smoke emitting site, and aging were found to have a large effect on the smoke particle size distribution. Mass and number concentrations of smokes from cotton lamp wick as a function of smoke obscuration in the standard UL 217 detector test chamber were determined. The maximum alarm threshold obscuration of $0.06 \mathrm{oD} / \mathrm{m}$ ( $4 \%$ per $\mathrm{ft}$ ), required for detector approval, was found to correspond to lamp wick aerosol mass concentration of $40 \mathrm{mg} / \mathrm{m}^{3}$ and particle concentration of about $4 \times 10^{6} \mathrm{~cm}^{-3}$ with the peak size in the number distribution of about $0.15 \mu \mathrm{m}$. The present UL 217 test method was shown to be affected by smoke coagulation and did not provide a complete measure of sensitivity in smoke detectors. An algebraic model size distribution, with number and mass concentration the only free parameters, was shown to provide a good estimate for all the smoke size distributions measured.

Key words: Aerosol; mass concentration; number concentration; size distribution; smoke; smoke detector; test method; UL 217.

\section{INTRODUCTION}

An effective approach in reducing fire hazard to life and property is the use of earlywarning devices such as smoke detectors. Studies have shown that fatalities might be reduced by about $40 \%$ if detectors were installed in all houses [1] ${ }^{1}$. A more recent experimental study (1976) concluded that detectors would provide adequate life saving potential under most real residential fire conditions [2]. Because of low cost and in some cases building code requirements, the sale of smoke detectors has reached an estimated 8 million units in the United States for the current year, 1977 [3].

1 Numbers in brackets refer to the 11terature references 1 isted at the end of this paper. 
The purpose of this report is to provide some of the basic data necessary for the development of improved smoke detectors and improved detector test methods. The three areas treated in this report are the physical characterization of smoke particulates, smoke detector testing methodology, and smoke aging.

A very important area in smoke detector design technology is characterizing the smoke in terms of the attributes sensed by the detector, i.e., particle size distribution, number concentration, mass concentration, and refractive index of smokes. How the above parameters are affected by the nature of the smoke source, pyrolysis temperature, and alrflow at the generating site are also important and will be examined.

To measure the smoke characteristics, some newly available commercial instruments were used. Since these measurement techniques are relatively new, the methods used and their limitations are described in more detail than might normally be necessary.

A second area of importance in smoke detector technology is the efficacy of certain test methods for detector approval and specification. Currently, most state jurisdictions will approve for sale any detector listed (approved) by the Underwriters' Laboratories (UL). For acceptance testing, UL follows the test method UL 217 which specifies the minimum and maximum triggering levels in terms of light obscuration measured by a photometer in the specified smoke chamber [4].

Because detector sensitivity is a complex function of smoke particle size, its concentration, and refractive index, a test method based on obscuration alone cannot fully describe detector performance. For example, two detectors with identical alarm levels in the UL chamber may differ when exposed to other types of smoke in a real fire $[5,6]$. A better method suggested for performance specification may be the use of the response curve where the detector outputs are given as a function of particle size and concentration. Currently neither the manufacturers nor the purchasers use this kind of performance specification in describing smoke detectors.

A third area where information is needed to advance the art of detector design and siting selection is the problem of smoke aging. Because aerosol particles collide and coagulate continuously (aging), a rapld change in size distribution occurs under the high concentration level where the detectors operate. For example, by the time the smoke has arrived at the detector area on the ceiling, the particle size distribution of the smoke will have changed significantly from its original size. A model or method of calculating the effect of aging on polydispersed smoke of various types is therefore essential to predict smoke characteristics after it leaves its source.

Information from the study may also be applied to the false-alarm problem in the presentday detectors. A British study has shown that for every real fire there were three false 
alarms due to ambient aerosols including moisture, cooking vapor, cigarette smoke, dust, etc. [7]. The ambient aerosol-related false alarms are inherent in the present day detectors because they can not differentiate among various types of particles. In general, any aerosol containing a prerequisite concentration of particles in the size range of 0.01 to $5 \mu \mathrm{m}$ can trigger the detector. Although false alarm rates may be reduced by setting a higher threshold for alarm in the detector, the resulting increase in response time to real fire, may not be acceptable in a life safety situation. Therefore, to minimize false alarms from ambient aerosols, a new generation of detectors capable of differentiating among types of smokes is urgently needed.

This report will discuss the three areas mentioned above and will include some results based on measurements to date in the smoke aerosol laboratory at the Center for Fire Research (CFR).

\section{FIRE SMOKE PROPERTIES}

\subsection{Definition of Fire Smoke}

Smoke generated from fire-related sources consists of both gases and aerosols; however, smoke detection technology is primarily concerned with the aerosol component of smoke. Depending on the material burned and the condition in which it burns (smoldering or flaming) the smoke aerosol can have a wide range of properties including the following:

1. liquid drops or solid particles (possibly including an adsorbed liquid phase)

2. shape can vary from spherical to chain agglomerates

3. optical properties vary from very absorbing for the black sooty smoke to almost transparent for some smokes from smoldering fires.

From a detection point of view, the msot significant property of the smoke aerosol is its size distribution. The particle size of interest ranges from $0.005 \mu \mathrm{m}$ to $5 \mu \mathrm{m}$. Smoke does not consist of only a single particle size but may have a range of particle sizes with peak concentration at a certain size. For a typical punk smoke, the peak concentration is on the order of 500 times higher than the concentration at a particle size ten times larger than the peak size (i.e. the concentration, $\Delta N / \Delta \log D_{p}$, at $0.1 \mu \mathrm{m}$ is $5 \times 10^{6} \mathrm{~cm}^{-3}$ compared to only $1 \times 10^{4} \mathrm{~cm}^{-3}$ at $\left.1 \mu \mathrm{m}\right)$.

This study was confined to particle concentration ranges on the order of the detector threshold for alarm. In the UL chamber the alarm threshold is defined in terms of smoke obscuration by smoke generated from a smoldering lamp wick. Obscuration is expressed in terms of optical density (OD) per meter (percent per foot in the UL 217 method).

$$
\text { Obscuration }=\left(\log I_{0} / I\right) / d \text {, }
$$




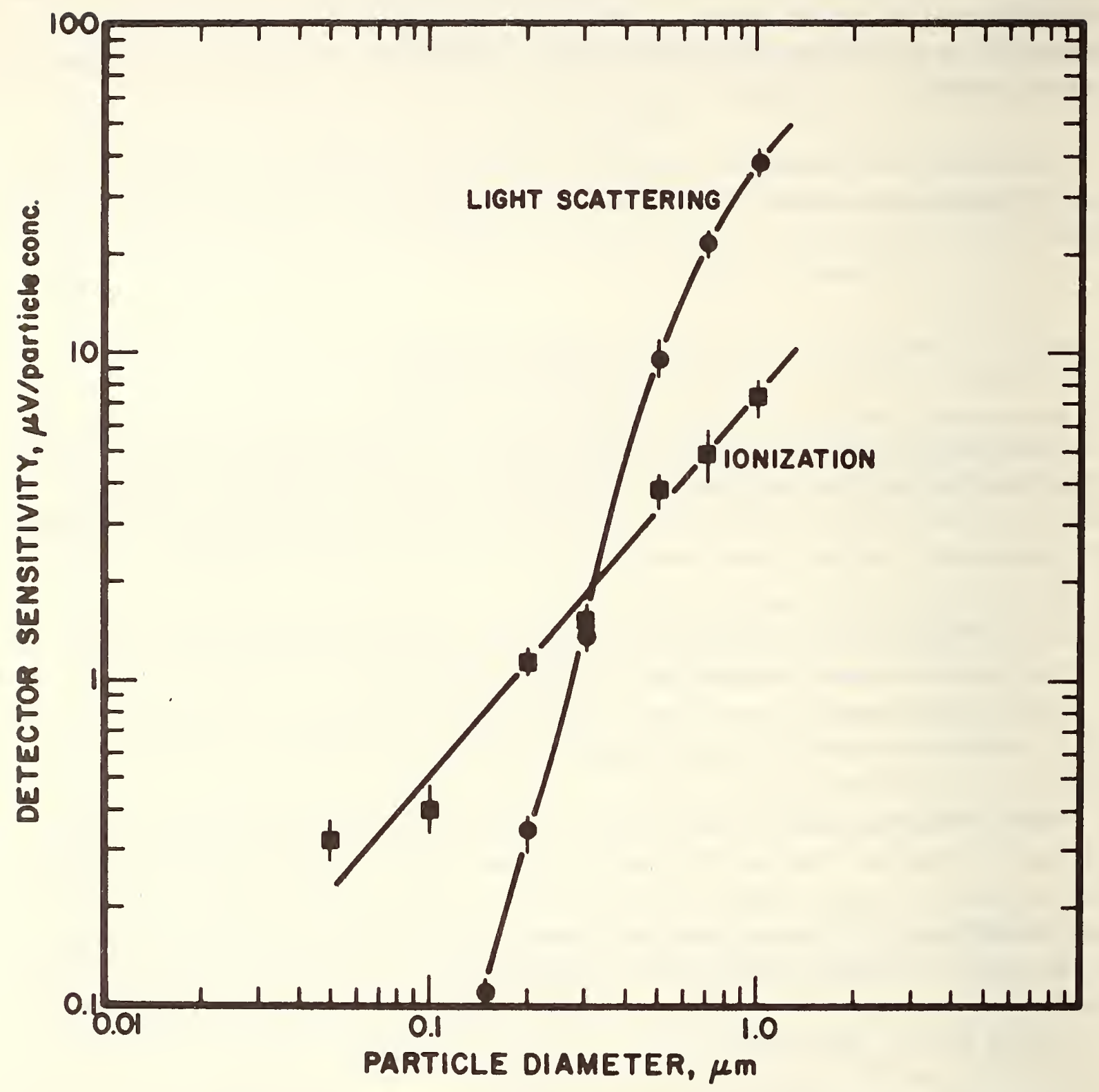

Figure 1. Detector sensitivity for two types of detectors exposed to monodisperse aerosols 
where I is the intensity of the light beam (color temperature < 2000K) penetrating the smoke, $I_{0}$ is the intensity with no smoke present, and $d$ is the path length. The maximum alarm threshold set by the Underwriters' Laboratories $(0.06 \mathrm{oD} / \mathrm{m}$ or $4 \%$ per $\mathrm{ft}$ ) was found to correspond to a number concentration of approximately $4 \times 10^{6} \mathrm{~cm}^{-3}$ with a geometric mean diameter of $0.14 \mu \mathrm{m}$, a geometric standard deviation of 1.7 (to be discussed), and a mass concentration of about $40 \mathrm{mg} / \mathrm{m}^{3}$ for lamp wick smoke. The desirability of expressing the alarm threshold by using the intrinsic aerosol properties instead of the optical density will be discussed later.

\subsection{Particle Size and Its Distribution}

The sensitivity of the present day smoke detectors depends strongly on the particle size of the aerosol. These detectors will respond to particles in the size range of 0.005 to $5 \mu \mathrm{m}$. However, the degree of sensitivity of particle sizes within this range differs considerably among the types of detectors and depends primarily on the physical principle on which the detector operates. For example, the response of the light-scattering-type detector is roughly proportional to the 6 th power of the particle diameter for particles smaller than a few tenths of a micrometer; whereas, for the ionization-type detector, the response is approximately a linear function of particle diameter. The commercial light-scattering-type detectors are practically insensitive to particles less than $0.1 \mu \mathrm{m}$ compared to the ionization type which can respond to particles as small as $0.005 \mu \mathrm{m}$. The light-scattering types are also sensitive to the refractive index of the smoke.

Since detector sensitivity is strongly size-dependent as illustrated in figure 1 , information on particle size of smokes and factors that control it are therefore needed for design of better detectors. In figure 1, the response of two typical smoke detectors are plotted as a function of particle size for monodisperse dioctyl phthalate aerosols in the number concentration range $10^{4}$ to $10^{6} \mathrm{~cm}^{-3}$ [8].

There are many ways for representing the size of a collection of particles. The choice of the size distribution variable is mainly a choice of convenience. In this paper, data are presented in terms of $\Delta N / \Delta \log D_{p}$ versus $D_{p}$ in a $\log -\log p 10 t$, where $N$ is a number of aerosol particles per cubic centimeter and $D_{p}$ is particle size in micrometers.

Such a plot is necessitated by the wide range in particle size and concentration. The quantity $\Delta N$ represents the number of aerosol particles in the particle diameter size range $\log \mathrm{D}_{\mathrm{p}}$ to $\log \mathrm{D}_{\mathrm{p}}+\Delta \log \mathrm{D}_{\mathrm{p}}$. The $\Delta$ presentation was used because data obtained from the measuring instruments were based on the average within each discrete range.

For example, the size distribution of a typical smoke is plotted in figure 2, where $\Delta \log \mathrm{D}_{\mathrm{p}}$ for each of the 9 discrete size ranges equals 0.25 . Then the total concentration for a given size range would equal $0.25 \times\left(\Delta N / \Delta \log D_{p}\right)$. The dotted portion of the curve represents a large uncertainty. 


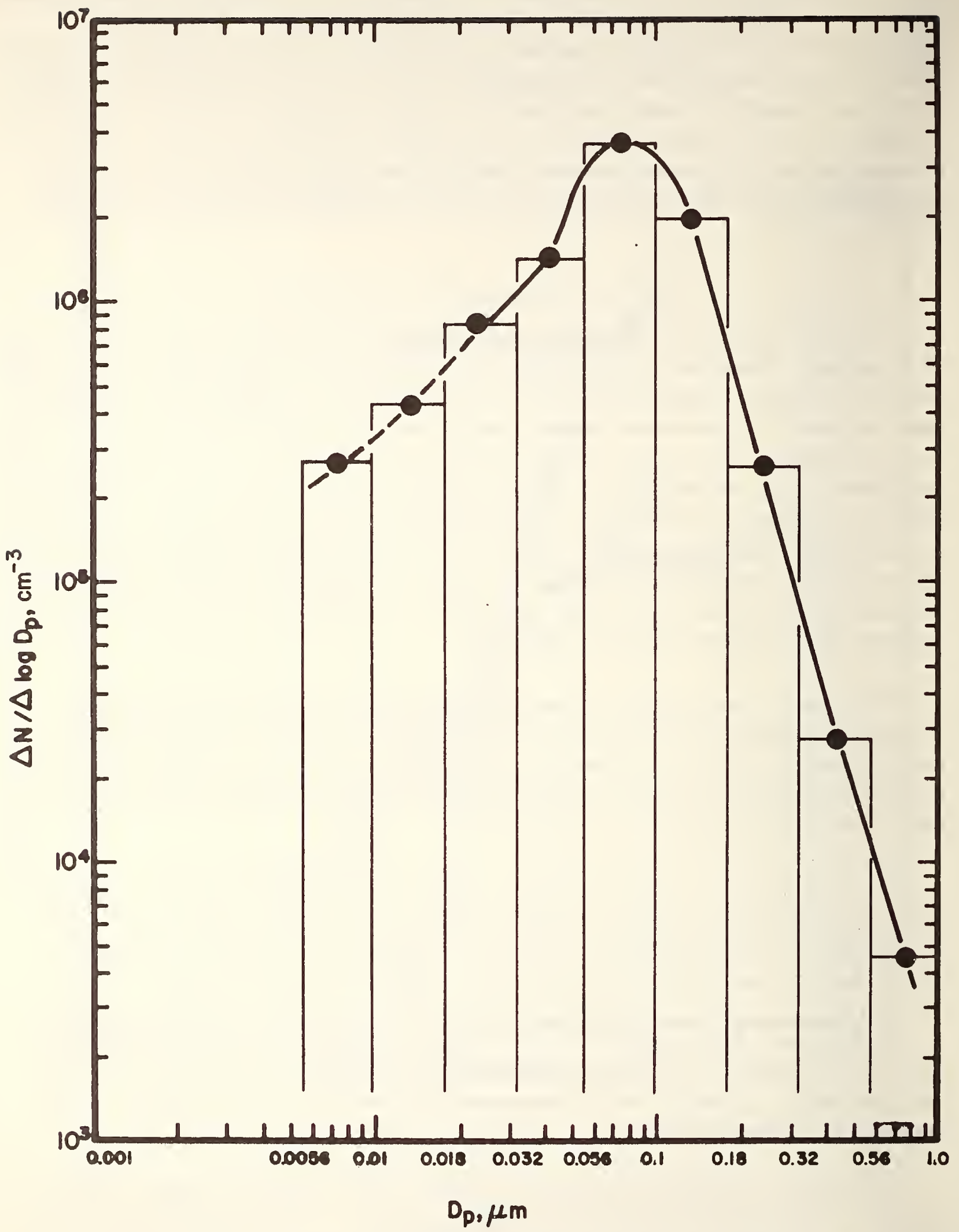

Figure 2. Discrete size ranges of the Electrical Aerosol Analyzer 
In many applications, the important characteristics of a size distribution may be given by the average particle size and the spread (or shape) of the distribution. It is convenient to use the geometric mean diameter, $\overline{\mathrm{D}}_{\mathrm{g}}$, as a measure of the average size.

$$
\begin{aligned}
& \log \bar{D}_{g}=\frac{\sum_{i=1}^{n} \Delta N_{i} \log D_{i}}{N} \\
& \overline{\mathrm{D}}_{\mathrm{g}}=\left[\mathrm{D}_{1}^{\Delta \mathrm{N}_{1}} \mathrm{D}_{2}^{\Delta \mathrm{N}_{2}} \mathrm{D}_{3}^{\Delta \mathrm{N}_{3}} \cdot \ldots \mathrm{D}_{1}^{\Delta \mathrm{N}_{1}}\right]^{1 / \mathrm{N}}
\end{aligned}
$$

where $\mathrm{N}$ is the total number of particles and $\Delta \mathrm{N}_{i}$ is the number of particles in the ith interval. For the size distribution plotted in figure $2, \bar{D}_{\mathrm{g}}=0.072 \mu \mathrm{m}$.

The spread of the size distribution is measured by the geometric standard deviation, ${ }^{\sigma} g^{\prime}$

$$
\log \sigma_{g}=\left[\frac{\sum_{i=1}^{n}\left(\log D_{i}-\log \bar{D}_{g}\right)^{2} \Delta N_{i}}{N}\right]^{1 / 2}
$$

This equation is based on log-normal distribution, which is the same as a normal or Gaussian distribution except that $\log \mathrm{D}_{\mathrm{p}}$ is normally distributed instead of $\mathrm{D}_{\mathrm{p}}$. The calculated standard deviation is $\log \sigma_{g}$ (a dimensionless number). If the aerosol were perfectly monodisperse, $\sigma_{g}$ would have a value of $1\left(\log \sigma_{g}=0\right)$. For a 1 og-normal distribution, $68.3 \%$ of the total particles are in the size range $\log \overline{\mathrm{D}}_{\mathrm{g}} \pm \log \sigma_{\mathrm{g}}$. In the case shown in figure 2 , where $\overline{\mathrm{D}}_{\mathrm{g}}=0.072$ and $\sigma_{\mathrm{g}}=1.75,68.3 \%$ of the total particles are in the range of 0.04 and $0.13 \mu \mathrm{m}$.

The usefulness of the parameters $\bar{D}_{g}$ and $\sigma_{g}$ as characteristic parameters for size distribution depends on how close the actual size distribution is to a log-normal size distribution given by:

$$
\frac{\mathrm{dN}}{\mathrm{d} \log \mathrm{D}}=\frac{\mathrm{N}_{\mathrm{t}}}{\sqrt{2 \pi} \log \sigma_{\mathrm{g}}} \exp -\left[\frac{\log \mathrm{D}-\log \overline{\mathrm{D}}_{\mathrm{g}}}{\sqrt{2} \log \sigma_{\mathrm{g}}}\right]^{2}
$$

Many particle size distributions are at least approximately log-normal [9].

The algebraic distribution, a modified version of the Junge distribution, which itself has been widely used for characterizing size distributions of atmospheric aerosols, is given by:

$$
\frac{d N}{d \log D}=\frac{a D^{3}}{\left(b+D^{3}\right)^{2+\varepsilon}}
$$


In this case the exponent $\varepsilon$ is a measure of the shape of the distribution, and the parameters $\underline{a}$ and $\underline{b}$ can be related to the number concentration, $\mathrm{N}_{t}$, and volume concentration, $V$, of the aerosol. In previous work [10] it was found that the size distribution of smoke generated from flaming $\alpha$-cellulose and smoldering punk fit the above form with $\varepsilon=0$. The size distribution expressed in terms of the aerosol parameters is given in reference [10]:

$$
\frac{\mathrm{dN}}{\mathrm{d} \log \mathrm{D}}=1.38 \frac{\mathrm{V} \mathrm{D}}{\left(\mathrm{D}^{3}+0.2 \frac{\mathrm{V}}{\mathrm{N}}\right)^{2}}
$$

It should be pointed out that the distribution breaks down for large particle sizes, because the total aerosol volume as determined by integrating eq. (6) over all particle sizes is infinite.

In this report both the log-normal distribution and the algebraic distribution will be compared with experimental results in Section 6.5 .

\subsection{Number Concentration and Mass Concentration}

In addition to particle size distribution total particle number concentration and mass concentration per unit volume are also important and useful characteristics of smokes. For a given particle size, the response of both the ionization and light-scattering types of detectors are linear functions of the particle number concentration and its associated mass up to a limiting number density.

Because of particle coagulation in the concentration range of interest, the number concentration of an aerosol decreases rapidly with time and creates a measurement problem for an instrument requiring scanning type over several minutes. On the other hand, the mass concentration is much more stable and can be readily measured with good precision. Wall loss, the primary loss mechanism for particle mass, is rather small compared to coagulation loss. For example, the mass concentration of smoke generated from smoldering punk decreased by less than $25 \%$ over a two-hour period during which time the number concentration dropped by at least a factor of 10 in a $1.8 \mathrm{~m}^{3}$ cubical aerosol chamber. Both the number and mass concentration properties of the smoke were measured to determine the mean particle diameter for comparison with other methods.

\section{MEASUREMENT METHODS}

Several types of instruments were used to characterize the particle size distribution, number concentration, mass concentration, and optical density of smokes under study. Most of these instruments have become commercially available only recently. 
As recently as a few years ago, the measurement of the s1ze distribution of submicron particles was both difficult and time consuming. As a result of research and development support provided by the Environmental Protection Agency and other public agencles, commercial 1nstruments have been developed to the point that such measurements are becoming rout1ne. Among the most useful instruments are the electrical aerosol size analyzer, the opt1cal particle counter, the plezoelectric mass monftor, and the condensation nuclei counter.

Each Instrument used in this work w111 be discussed briefly in terms of the princ1ple under which the 1nstrument functions, 1ts 11m1tations, measurement ranges, and prec1s1on. The reported data w111 be examined In light of these known $11 \mathrm{~m} 1$ tations.

The performance of the Instruments are summar1zed in Table 1. For a more complete description, the reader is referred to references given in this paper. Other recent advances in particle measurement techniques have been reported in the proceedings of a symposium at the University of Minnesota [11] and elsewhere [12].

\subsection{Particle Size Distribution - 0.006 to $1 \mu \mathrm{m}$}

The Electrical Aerosol Analyzer (EAA), the maln instrument in this study, was used to measure the size and concentration of smoke aerosol in the 0.006 to $1.0 \mu m$ diameter range. Its operation is based on the "diffusion charging-mobility analysis" principle first described by Whitby and Clark [13]. Such charging is characterized by ion-particle collisions resulting from the thermal motion of the ions. The electrical mobillty of an aerosol charged under conditions closely approximating that of "diffusion" charging in the EAA is a monotonically decreasing function of the particle size for particle sizes smaller than about one micrometer in diameter.

The instrument samples the aerosol at a constant rate of 4 liters per minute and at concentration as high as $2 \times 10^{6}$ particles per cubic centimeter for particles with $\overline{\mathrm{D}}_{\mathrm{g}}=0.1 \mu \mathrm{m}$ without the need for sample dilution. For smaller particle sizes, the instrument can handle higher number concentrations. However, for smoke concentrations at detector threshold level $\left(10^{6}-10^{7} \mathrm{~cm}^{-3}\right)$, a tenfold or more sample dilution was necessary.

A detailed description of the instrument is given elsewhere [14,15]. Essentially, aerosol entering the analyzer is first exposed to unipolar positive ions and becomes electrically charged. Using the relationship between particle mobility and size mentioned earlier, the size distribution of the aerosol can be calculated from the mobility distribution measured by the mobility analyzer. 


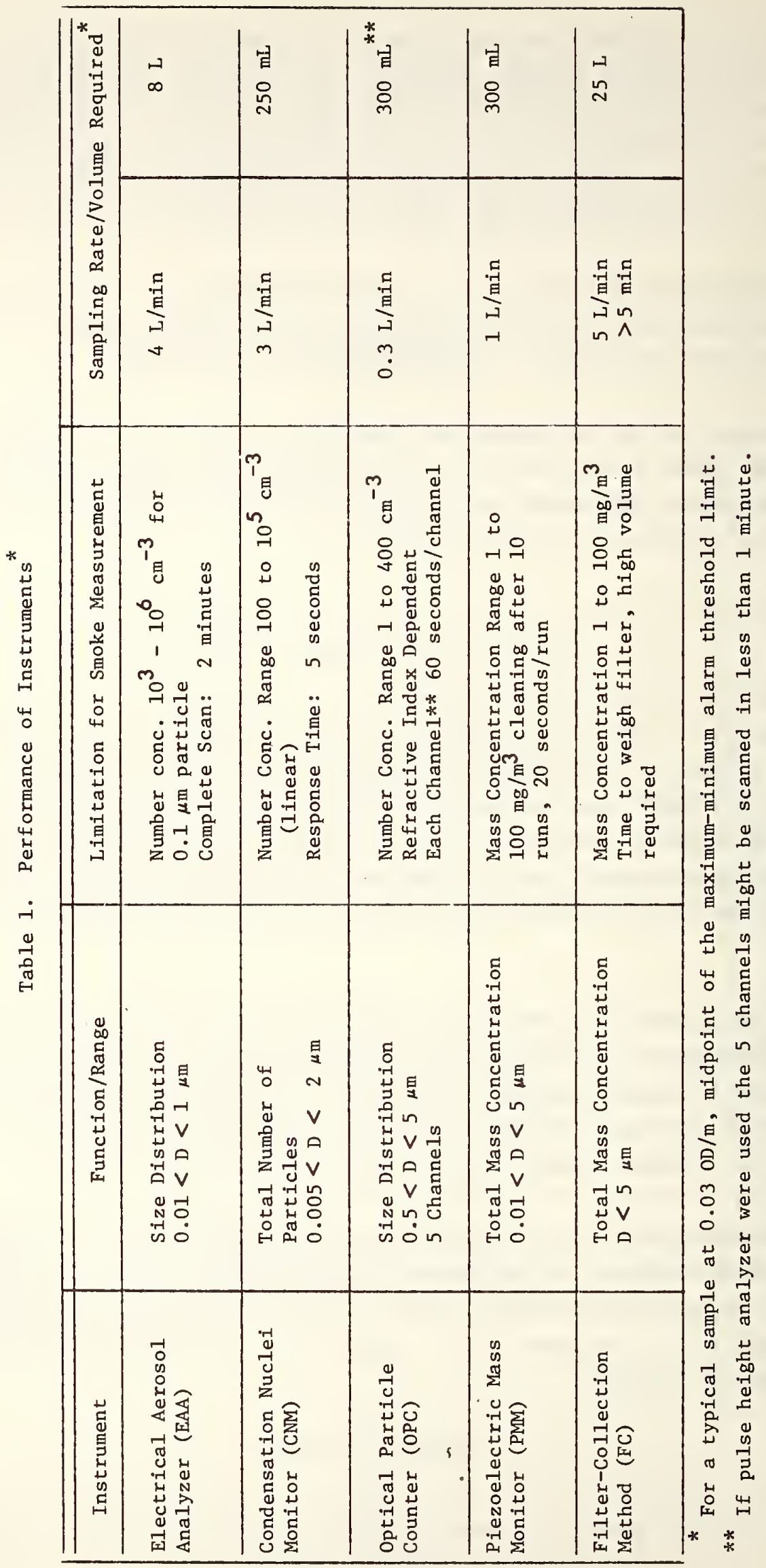


The mobility analyzer is in the form of a cylindrical condenser surrounded by clean sheath air. Aerosol outside the sheath flows down in a laminar stream. The charged aerosol is deflected through the sheath air by the voltage applied on the center electrode. For a given voltage on the center rod, particles above a certain critical mobility (smaller than certain critical size) are precipitated while those with lower mobility (larger particles) escape and are sensed by the electrometer sensor. By changing the voltage on the center rod and measuring the corresponding electrometer current, the mobility and thus the size distribution of the aerosol can be determined. The standard operating condition of the instrument provides appropriate voltage steps to divide the size range of the instrument into nine equal geometrical intervals of four intervals per decade in particle size ranging from $0.006 \mu \mathrm{m}$ to $1.0 \mu \mathrm{m}$. The complete voltage sequence can be scanned in about 2 minutes. The digital output of the instrument can either be recorded or fed directly into a minicomputer for processing.

Precision and Calibration

The absolute calibration of the instrument was performed by monodisperse aerosols of known concentration generated from a mobility classifier having sizes corresponding to the geometric mean diameter of each channel of the EAA [14]. The geometric standard deviation, $\sigma_{g}$, of the EAA response to each monodisperse sample varies from 1.0 for the two smallest size ranges to 1.8 for the two largest size ranges [16]. Because of the large $\sigma_{g}$ for the last few channels, the EAA is most reliable for measuring size distribution for polydisperse aerosols $\left(\sigma_{g}>1.5\right)$ and not for monodisperse or near monodisperse aerosols. For best results, the EAA should not be used for aerosols with a peak size in the number distribution greater than $0.2 \mu \mathrm{m}$.

\subsection{Particle Size Distribution 0.5 to $5 \mu \mathrm{m}$}

Particles between 0.5 and $5 \mu \mathrm{m}$ were measured by an optical particle counter that counts individual particles (OPC). In this instrument, a beam of light is focused into a small viewing volume through which the airborne particles pass one at a time. The amount of light scattered from each individual particle is measured by a photodiode detector. The detector signals (pulse height), which are monotonically related to the size of each particle, are then sorted and stored in channels of the multi-channel analyzer of the instrument. In instruments without the multi-channel analyzer, only the pulse heights of selected ranges are counted and displayed one at a time. Thus the operator can manually select the size range and record the count frequency for each range to determine size distribution of the aerosols.

The commercial instrument for the present study $[17,18]$ measured scattered light falling in the cone between $8^{\circ}$ and $20^{\circ}$ with respect to the direction of the incident beam. The viewing volume was about $0.5 \mathrm{~mm}^{3}$ while sample flow rate was about $0.3 \mathrm{~L} / \mathrm{min}$. To prevent sample deposit on the optics and wall of the cell, clean sheath air surrounds the aerosol sample stream through the viewing volume. 
The OPC can measure aerosol number concentrations as high as $400 \mathrm{~cm}^{-3}$ for particles between 0.5 and $5 \mu \mathrm{m}$. To avoid coincident counting error, aerosols with concentrations greater than about $400 \mathrm{~cm}^{-3}$ are diluted prior to the measurement. High dilution (x50) was required for sampling smoke aerosol. Smoke containing a large concentration of particles smaller than $0.5 \mu \mathrm{m}$, even after the prerequisite dilution, did not appear to affect the measurement.

Though the OPC is a convenient measurement tool, its reliability depends strongly on its calibration. The size indicated by the counter is equivalent to the size of the calibration aerosol, usually a spherical and transparent aerosol such as polystyrene latex spheres. The shape and refractive index, $m$ (real and imaginary part), of the measured particles may be different from that of the calibration aerosol so that the true size may be different from the one indicated by the counter. For example, it has been predicted for an instrument similar to this that a $2 \mu \mathrm{m}$ non-absorbing particle with refractive index $\mathrm{m}=1.54$ produces the same signal as a $4 \mu \mathrm{m}$ absorbing particle with $\mathrm{m}=1.54-1.0 \mathrm{i}$, where the second term is the imaginary or absorbing part of the refractive index [19]. This shows that all particle size data need to be interpreted with caution and with due consideration for the limitations of the methods used.

\subsection{Number Concentration 300 to $10^{7} \mathrm{~cm}^{-3}$}

To measure the number concentration of smoke aerosols with a wide range of particle size from 0.005 to $2 \mu \mathrm{m}$ and at moderate concentration, a condensation nuclei monitor (CNM) [20] was used. The instrument has 6 linear scales covering the number concentration range 1,000 to $300,000 \mathrm{~cm}^{-3}$ and a non-linear range extending up to $10^{7} \mathrm{~cm}^{-3}$. The sample rate is about $3 \mathrm{~L} /$ min with continuous analog display of the particle concentration.

The instrument operates on the principle of a cloud chamber in which water is condensed upon submicron particles to provide micron size droplets. A constant flow volume of sample is periodically diverted through a humidifier and then into a cloud chamber where a fixed volume expansion of the sample occurs. A cloud is thus produced by the $300 \%$ supersaturation in the presence of the particles. Each large water particle grows from a single nucleus of the smoke to a certain finite size.

The concentration of the cloud is measured by the attenuation of a light beam which traverses the chamber and is focused on a silicon photodiode. After expansion, the cloud chamber is pressurized and flushed out. The total measurement cycle time is approximately one second.

The instrument has a high degree of repeatability, better than $\pm 5 \%$ of full-scale on the linear range (0-300K). The accuracy of the instrument is dependent on the primary calibration standard. The manufacturer claims an accuracy of $\pm 20 \%$ based on the Pollak counter as the standard; however, Liu et al. found a factor of about two difference between the nuclei counter and their standard, the mobility classifier [21]. 


\subsection{Mass Concentration}

\section{Mass Monitor Method}

To determine the mass concentration of smoke aerosol, both the particle mass monitor and the filter collection method were used.

The mass monitor is based on the high sensitivity of the resonant frequency of a quartz crystal to changes in mass due to deposition of particles on the crystal surface. In practice, the aerosol is drawn into the electrostatic precipitator chamber of the monitor at a flow rate of $1 \mathrm{~L} / \mathrm{min}$ by a vacuum source. The particles in the sample stream are deposited onto the surface of a piezoelectric quartz crystal by a highly efficient electrostatic precipitator. The resonant frequency of the quartz crystal decreases linearly with the total mass of the particle deposition, thereby providing a measure of the mass concentration. A second or reference quartz crystal, located downstream of the flow, compensates for possible changes in temperature and gas composition in the flow cell. Thus the time rate-of-change of the output frequency signal is directly proportional to the total particle mass concentration.

The commercial monitor [22] is capable of sampling mass concentration between 1 and 60 $\mathrm{mg} / \mathrm{m}^{3}$ at size range from 0.01 to $10 \mu \mathrm{m}$. The frequency can be measured precisely to $\pm 1 \mathrm{~Hz}$, and this is equivalent to a mass concentration resolution of $0.005 \mathrm{mg} / \mathrm{m}^{3}$ for a one-minute measuring period. The particle mass concentration for this instrument may be calculated as follows:

$$
C=\frac{1}{S Q E_{C} E_{W}} \frac{\Delta f}{\Delta t}=333 \frac{\Delta f}{\Delta t}
$$

where $\mathrm{C}$ is in $\mu \mathrm{g} / \mathrm{m}^{3}, \Delta \mathrm{f}$.in $\mathrm{Hz}, \Delta t$ in seconds, $Q$ sampled aerosol flow rate in $\mathrm{m}^{3} / \mathrm{s}, \mathrm{E}_{\mathrm{C}}$ is the collection efficiency, and $E_{w}$ is the efficiency for weighing the deposited particles. The factor 333 is obtained assuming a flow rate of $1 \mathrm{~L} / \mathrm{min}$ and unity for $\mathrm{E}_{\mathrm{c}}$ and $\mathrm{E}_{\mathrm{w}}$. The mass sensitivity, $S$ is given by $[23,24]$ :

$$
S=\frac{\Delta f}{\Delta m}=-\frac{N}{b^{2} \rho A}
$$

where $b$ is the thickness of the quartz crystal, $m$ is mass of collected aerosol, $\rho$ is the density of the crystal $\left(2.65 \mathrm{~g} / \mathrm{cm}^{3}\right)$, A is the area of the crystal, and $\mathrm{N}$ is the frequency constant of AT - cut quartz $(0.166 \mathrm{MHz} \mathrm{cm})$. An $\mathrm{S}$ of $180 \mathrm{~Hz} / \mu \mathrm{g}$ is given in the instrument manual. As a typical example, an aerosol with a mass concentration of $40 \mathrm{mg} / \mathrm{m}^{3}$ produces a frequency shift of about $1200 \mathrm{~Hz}$ in 10 seconds. 
To minimize error. caused by the $\pm 1 \mathrm{~Hz}$ measurement uncertainty, sampling time $\Delta \mathrm{t}$ has to be sufficiently long for low concentration aerosol. For example, a sampling time of at least 33 seconds is required for a $1 \mathrm{mg} / \mathrm{m}^{3}$ aerosol in order to reduce the error to the $\pm 1 \%$ level.

To assure $100 \%$ collection efficiency for liquid phase aerosols a trace amount of vapor (proprietary, available from only one known supplier) was allowed to diffuse into the inlet aerosol stream and act. as a conditioning agent for the particles. This vapor adheres in one or two monolayers to the particles. The liquid monolayer is extremely hydrophilic and consequently absorbs additional monolayers of water if available. These layers decrease the electrical sensitivity of the particles and make the particles adhere firmly to the crystal. The crystal requires cleaning when its total deposit from previous runs reaches 200 to $300 \mu \mathrm{g}$. Collection efficiency is not necessarily $100 \%$ for aerosols of solid particulates even. with the use of the conditioning vapor. In that case calibration using the filter-collection method is needed.

\section{Collection by Filter Method}

Teflon filters (type AA or FH, Millipore) $25 \mathrm{~mm}$ diameter and $0.5 \mu \mathrm{m}$ pore size, were used in the filter-collection-weighing method. The sampling rate, for the flows regulated by a critical orifice, was generally $4.9 \mathrm{~L} / \mathrm{min}$. The total sample mass was on the order of $0.5 \mathrm{mg}$ on a filter nominally weighing $24 \mathrm{mg}$.

This weighing method was inherently more accurate than the mass monitor though it. required a large volume of sample and was less convenient. The method was used to calibrate the mass monitor and replaced it for certain types of smoke that did not rigidly adhere to the collection surface of the monitor.

Though filter pore size was 0.5 or $0.2 \mu \mathrm{m}$, particles as small as $0.01 \mu \mathrm{m}$ are also collected with nearly $100 \%$ efficiency due to the diffusion mechanism $[25], \because$

\subsection{Aerosol Chamber}

In order to minimize wall losses, a relatively large chamber was constructed for the generation and retention of smoke under study: The chamber was a $1.25 \mathrm{~m}$ cube with inside surfaces consisting of smooth plastic panels. Small ports in the cube provided access for sampling, air inlet, exhaust, viewing as well as insertion and control of the smoke generating source.

A photometer with a path length equal to the full. height of the cube was located near the center of the chamber. The light source was a 15-watt incandescent lamp operating at a color temperature of approximately $2200 \mathrm{~K}$. The beam was uniformly collimated and has a width of about $25 \mathrm{~mm}$. The light detector has a P-39 phototube with S-4 sensitivity curve. The output current from the phototube in series with $67.5 \mathrm{~V}$ dry cell battery, was measured by 
a digital picoameter. The photometer system was sufficiently stable that a light beam attenuation of $0.1 \%$ could be determined.

There were provisions for control of inlet air in terms of residual particle concentrations and humidity. Prior to generation of smoke, the residue particle concentration of filtered and dried air in the chamber was routinely maintained at less than 200 particles per cubic centimeter as measured by the condensation nuclei monitor. The humidity could be adjusted between $20 \%$ and $80 \%$.

The air-tight and rigid chamber was maintained at slightly positive pressure during sampling by feeding filtered air into it at a rate somewhat higher than the withdrawal rate by the analysis instruments. Since the total chamber volume was $1.8 \mathrm{~m}^{3}$, the effect of dilution caused by the sampling at $3-7 \mathrm{~L} / \mathrm{min}$ for a total period of 2 to 10 minutes was 1 ess than 5\% and was neglected. A $10-\mathrm{cm}$ diameter muffin fan in the chamber assured uniform distribution of aerosol in the chamber.

The chamber was subsequently modified to include a thin plastic bag section 1001 iters in volume extending above the chamber. The purpose of the inflatable bag was to maintain a constant pressure in the chamber during sample withdrawal without the need to replace it with air.

\subsection{UL 217 Smoke Detector Evaluation Chamber}

Testing of residential smoke detectors for approval is performed in the United States by two organizations; the Underwriters' Laboratories, Inc. (UL) and Factory Mutual Research Corp. (FM). Each organization publishes its own test method standards and a 1 ist of approved devices. The test method used by UL for testing both types of detectors is the UL 217 [4], while the method used by FM for testing the ionization and photoelectric type detectors is FM Class No. 3230-3250 [26].

Basically, these methods measure the light obscuration of a given type of smoke at the alarm threshold of the detectors. A minimum sensitivity of $0.06 \mathrm{OD} / \mathrm{m}$ ( $4 \%$ obscuration per ft for a 5-ft beam length in the UL 217 chamber) for grey-color (cellulosic) smoke and 0.14 $\mathrm{OD} / \mathrm{m}$ ( $10 \%$ per $\mathrm{ft}$ ) for black smokes (heptane) are required. There are no requirements based on absorption coefficient, particle size, or concentration in the test chamber. Since it is known that particle size as well as other properties of the smoke affect light absorption [27] and that the sensitivity to the properties varies, depending on the type of detector, the characteristics of the smokes used in these test methods are of particular importance and form a principal subject of this study. 


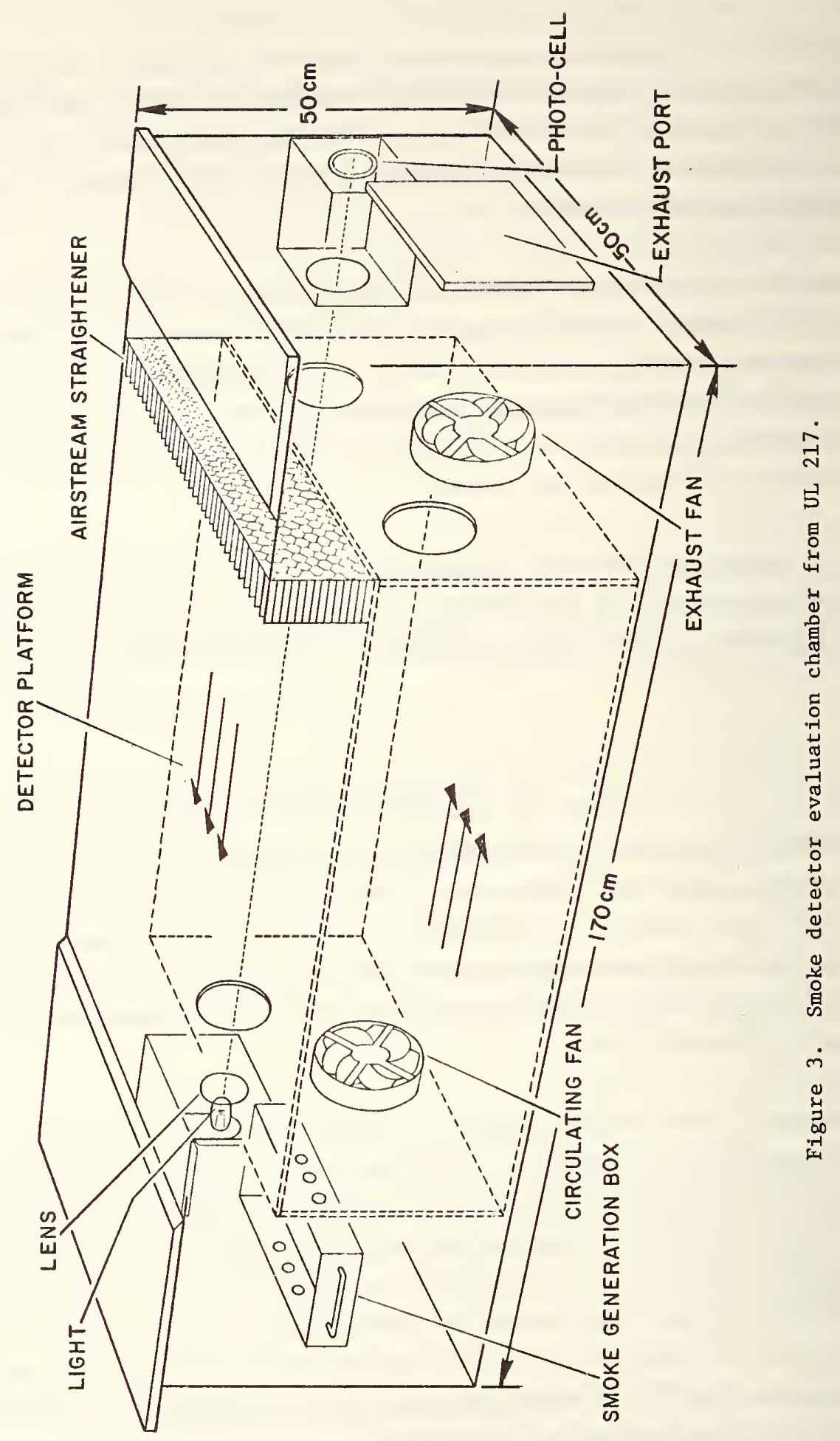


The detector evaluation chamber (UL 217) is essentially a 50 x 50 x $170 \mathrm{~cm} \mathrm{closed}$ horizontal box in which the smoke detector is mounted on the senter of the top surface as shown in figure 3. The chamber is partitioned into a top-and bottom-half sections by a platform extending almost the full length of the chamber. Smoke generated in the lnwer section is circulated through the box in the direction indicated by the arrows in $\mathrm{figure} 3$. $\mathrm{A}$ constant circulating velocity of $0.18 \mathrm{~m} / \mathrm{s}(35 \mathrm{ft} / \mathrm{min}$ ) is maintained.

A photometer which measures the Iight obscuration of the circulating smoke has a path length of $152 \mathrm{~cm}$ ( $5 \mathrm{ft}$ ) and a beam width of $5 \mathrm{~cm}$. It consists of an incandescent lamp (GE-4515) source operating on $2.4 \mathrm{~V}$ and a photovoltaic cell (Weston 594 RR) detector.

In the testing, smoke from a smoldering lamp wick or heptane flame in the closed chamber is allowed to accumulate to the triggering level of the smoke detector and was measured by the chamber photometer in terms of percent obscuration. Since the smoke source burns continuously, the concentration of the smoke in the chamber increases with time.

\section{AEROSOL SOURCE MATERIALS AND DILUTION}

Punk

Punk (imported from the Orient as incense sticks) was found to be a useful source of combustion aerosol. It consisted of a bamboo stick core with a square or rectangular cross section, 1 to $2 \mathrm{~mm}$ in width. A finely ground mixture of cellulosic materia1, binder, and oxidant coated the stick to a final diameter of about $3 \mathrm{~mm}$ and a length of about $160 \mathrm{~mm}$. After the igniting flame is extinguished, the punk stick smolders and self-propagates in a downward direction. The downward smoldering rate was found to be about $4 \mathrm{~mm} / \mathrm{min}$. Though it was a convenient source for high cencentration aerosol $\left(\sim 10^{11}\right.$ particle per minute at the peak size range between 0.1 and $0.17 \mathrm{\mu m}$ ), large variation in size and composition of the punk sticks were observed in single batches and resulted in a variation in the generation rate among the sticks. However, the peak particle sizes of fresh smoke appeared to be independent of the stick diameter.

\section{Lamp Wick}

Lamp wick, a knitted cotton strip $3 \mathrm{~mm}$ thick and $22 \mathrm{~mm}$ in width, is manufactured as wicks for kerosene lamps. In use, a strip about $4 \mathrm{~cm}$ in length was ignited and allowed to smolder from the bottom and burn upward. It was hung in the middle of a cylinder 5 cm in diameter and $7 \mathrm{~cm}$ high, constructed from 100 mesh metallic screen. The screen cylinder with the smoldering wick was then inserted into the UL 217 chamber to initiate the test. 


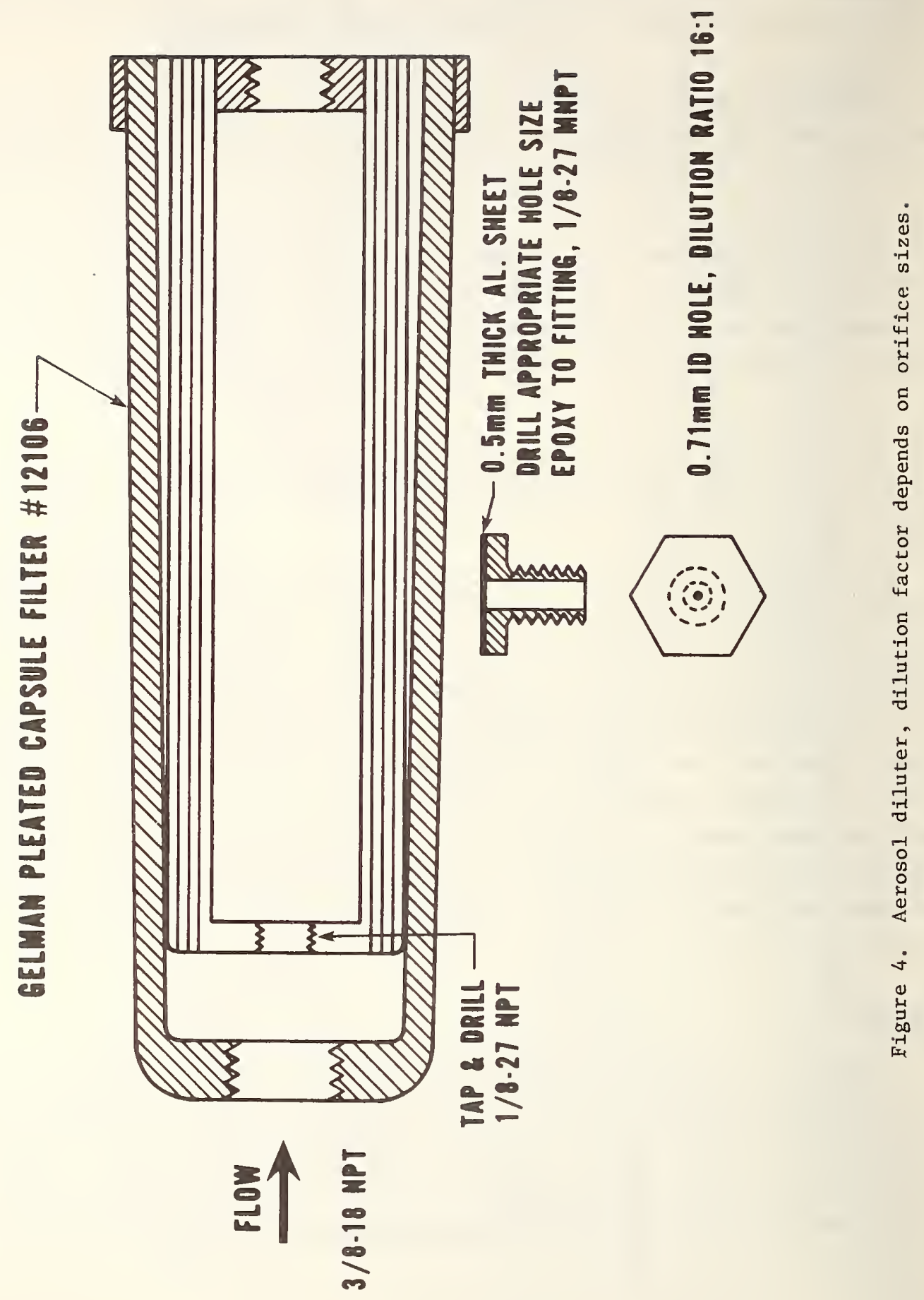


This material, similar to filter paper, consisted of pure $\alpha$-cellulose fibers from cotton linters. Samples $0.8 \mathrm{~mm}$-thick obtained from the NBS standard reference material SRM 1006 stock were cut into $6-\mathrm{mm}$ diameter discs with a mass of $8.6 \pm 0.17 \mathrm{mg}$ ( \pm standard deviation). For some experiments, larger pieces of this material were used.

\section{Heptane}

Black sooty smoke was generated by diffusion burning of heptane from the top of a wick, one end of which is soaked in heptane. The cotton wick bundle was imbedded inside and extended slightly above the top of a 20-mm long glass tube with an inside diameter of $3.5 \mathrm{~mm}$. The tubing extended about $6 \mathrm{~mm}$ above the surface of the cap which covered the heptane container.

\subsection{Method for Aerosol Dilution}

To keep within the measuring range of each instrument, aerosols above a certain concentration level were diluted prior to the measurement. A useful dilution technique was to pass the aerosol through a $0.2 \mu \mathrm{m}$ pore size pleated capsule filter cartridge (Gelman 12106) which was modified to include a small by-pass orifice. For ease of mounting and for ease in changing the orifice size, aluminum discs with different orifice sizes were constructed and cemented to one end of pipe fittings. The fitting could easily be screwed into the threaded hole of the plastic junction in the filter as shown in figure 4.

For a $0.71-\mathrm{mm}$ orifice the dilution ratio was about 16 ; this means that $1 / 16$ of the aerosol went through the orifice and the remaining 15/16 were filtered prior to rejoining the stream. As shown in figure 5 the filter did not significantly distort the size distribution of the aerosol. The dilution ratio for the smallest particle size $(0.042 \mu \mathrm{m})$ was found to be 15.4 compared to 18.1 for the largest particle size $(0.75 \mu \mathrm{m})$. No correction was made for this small variation.

\section{RESULTS}

\subsection{Smokes in the UL 217 Chamber}

The relationship between optical density (light obscuration), mass concentration, number concentration, and particle size distribution of lamp wick and heptane generated smoke were determined in the UL 217 chamber.

In these measurements, a smoldering lamp wick burning from bottom to top was held vertically in a holder and placed in the burner end of the chamber. The wick was withdrawn when the smoke reached a desired obscuration level, ranging from 0.005 to $0.08 \mathrm{oD} / \mathrm{m}$. After a 30-35 second waiting period to insure uniform mixing, the aerosol was sampled by the analyzers. 


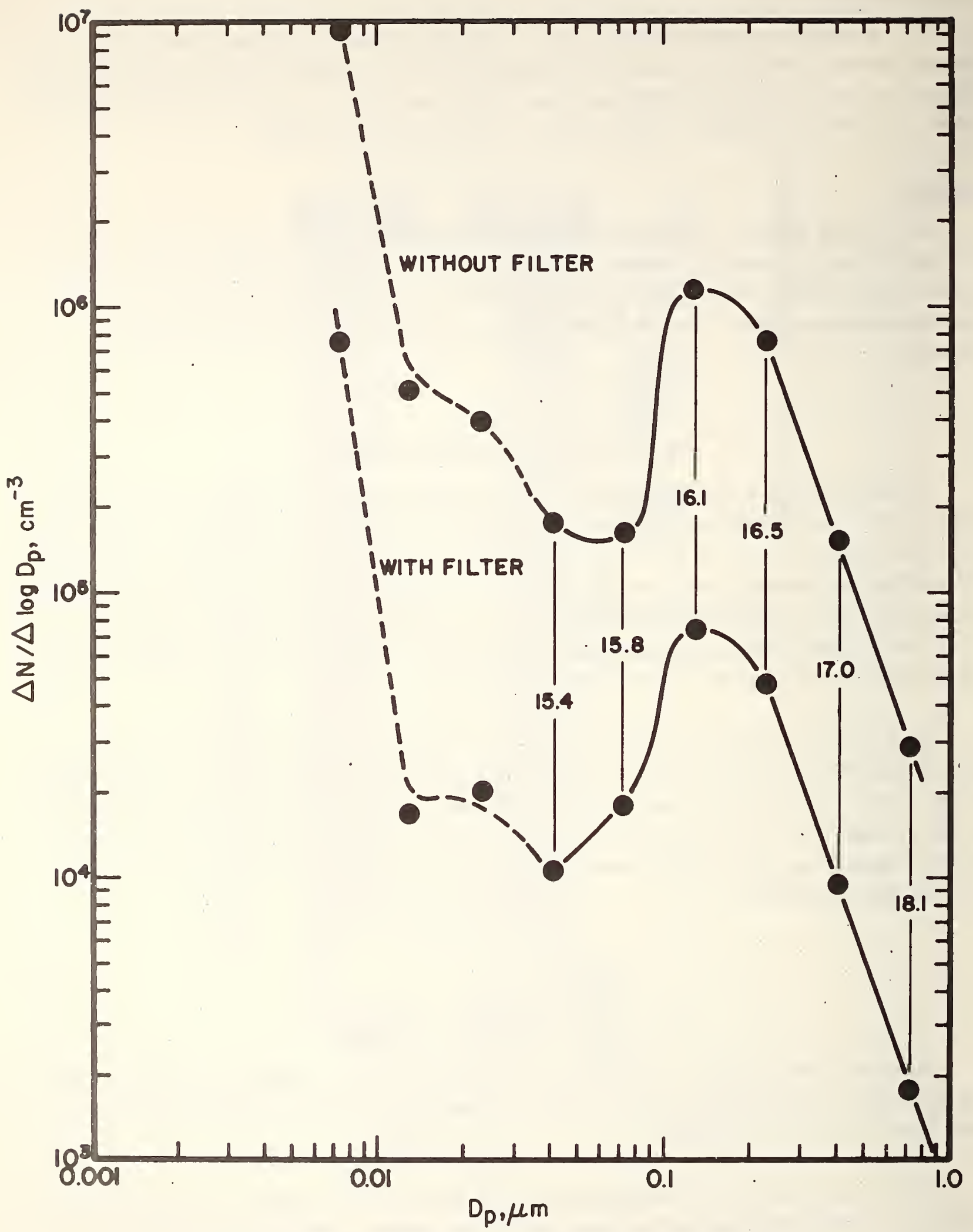

Figure 5. Size distribution of an aerosol before and after dilution. Numbers denote dilution ratios for each size range. 
In certain experiments, analysis was performed periodically as the aerosol continued to age in the chamber. A nominal flow velocity of $0.18 \mathrm{~m} / \mathrm{s}$ was maintained at the center of the detector platform throughout the experiment.

\section{Smoke Generation Rates}

The average rates of change in light attenuation during the aerosol build-up period were approximately $0.02 \mathrm{OD} / \mathrm{m}$ and $0.07 \mathrm{OD} / \mathrm{m}$ per minute for lamp wick and heptane aerosols, respectively. There were large variations in the generation rates probably caused by the nonuniformity of lamp wick construction and heptane burning.

\section{Mass Concentration}

Figure 6 shows the mass concentration as a function of light obscuration in the UL 217 chamber for aerosols generated from smoldering cotton lamp wick and from the heptane diffusion flame. The mass concentration for the lamp wick and the heptane aerosols were determined by using the quartz mass monitor and the filter-weighing method, respectively. The quartz mass monitor was not effective in collecting the heptane-generated aerosol.

Because of the 3 to 4 minute sampling period required to collect sufficient heptane particulate for precise weighing, there was a large shift in obscuration level during this period in the chamber. The shift was caused by aging as well as by aerosol dilution from air infusion into the small ( 350 liters) chamber to replace sample withdrawal. The extent of the shift is shown by the horizontal bars in figure 6 . As a result of this longer sampling period, in contrast to the shorter 20-30 second period used by the mass monitor, measurement uncertainty for the filter-collection method is expected to be larger than the mass monitor method in these experiments.

The inclusion of aerosol of various concentrations and ages has also increased the scatter of data points shown in figure 6.

\section{Number Concentration}

The condensation nuclei monitor (CNM) with a 16 to 1 diluter was used to measure the particle number concentration for the two types of aerosols generated in the UL 217 chamber. Figure 7 shows the concentration as a function of smoke obscuration for aerosols of different initial concentrations. Numbers adjacent to the data points denote the age of the aerosols, measured from the time the burning specimen was inserced into the chamber to the time the aerosol was sampled by the monitor. Numbers at the top of the curve also indicate the minimum time for generation to reach the indicated levels.

The analyses of a given aerosol as it aged are connected by the short curves. From these curves it can be shown that the light obscuration per particle increases with aging. For example, obscuration of lamp wick aerosols with almost identical concentration, $2.6 \mathrm{x}$ $10^{6} \mathrm{~cm}^{-3}$, was about $0.04 \mathrm{oD} / \mathrm{m}$ for a 2.7 -minute aerosol, but over $0.07 \mathrm{OD} / \mathrm{m}$ for an 8 -minute 


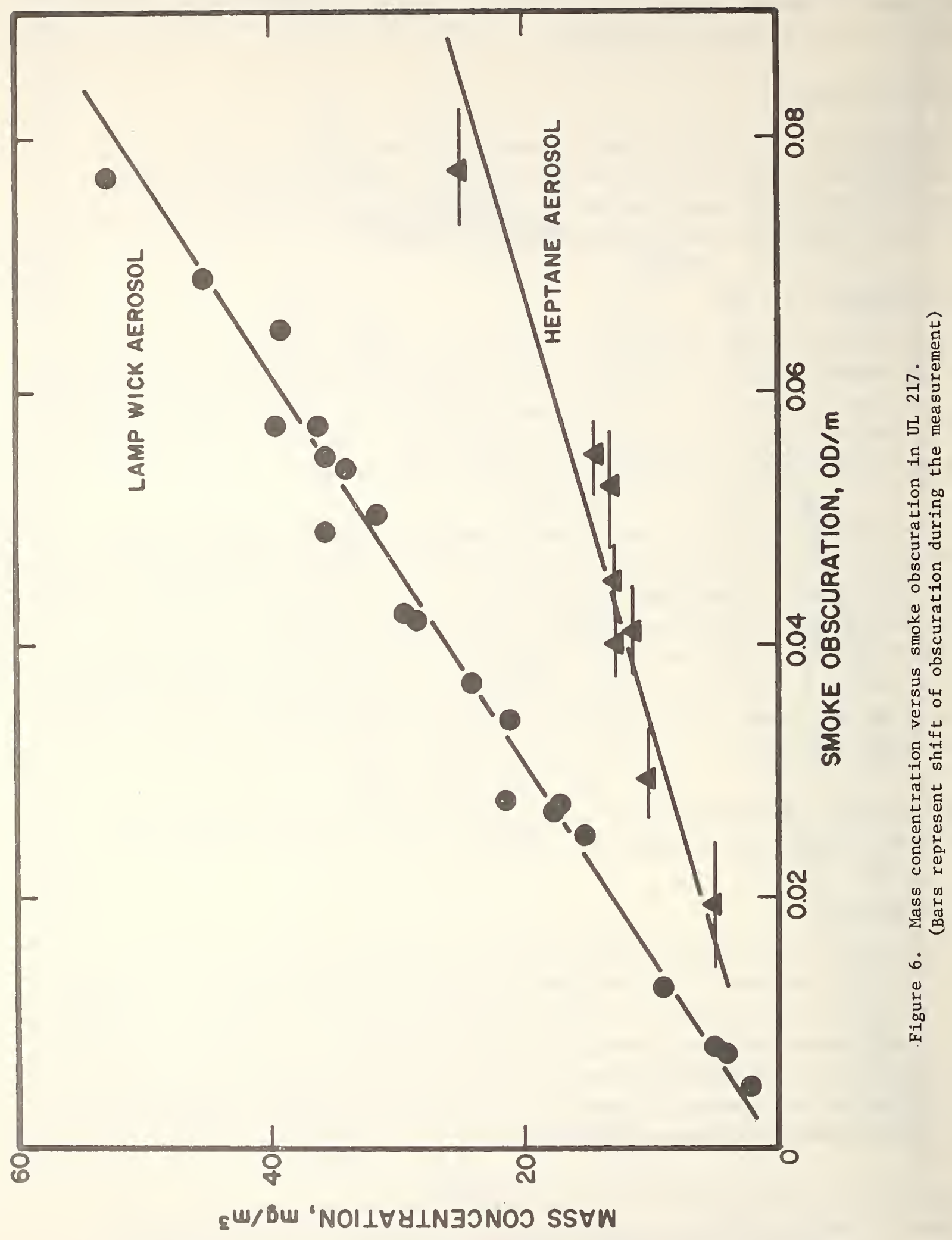




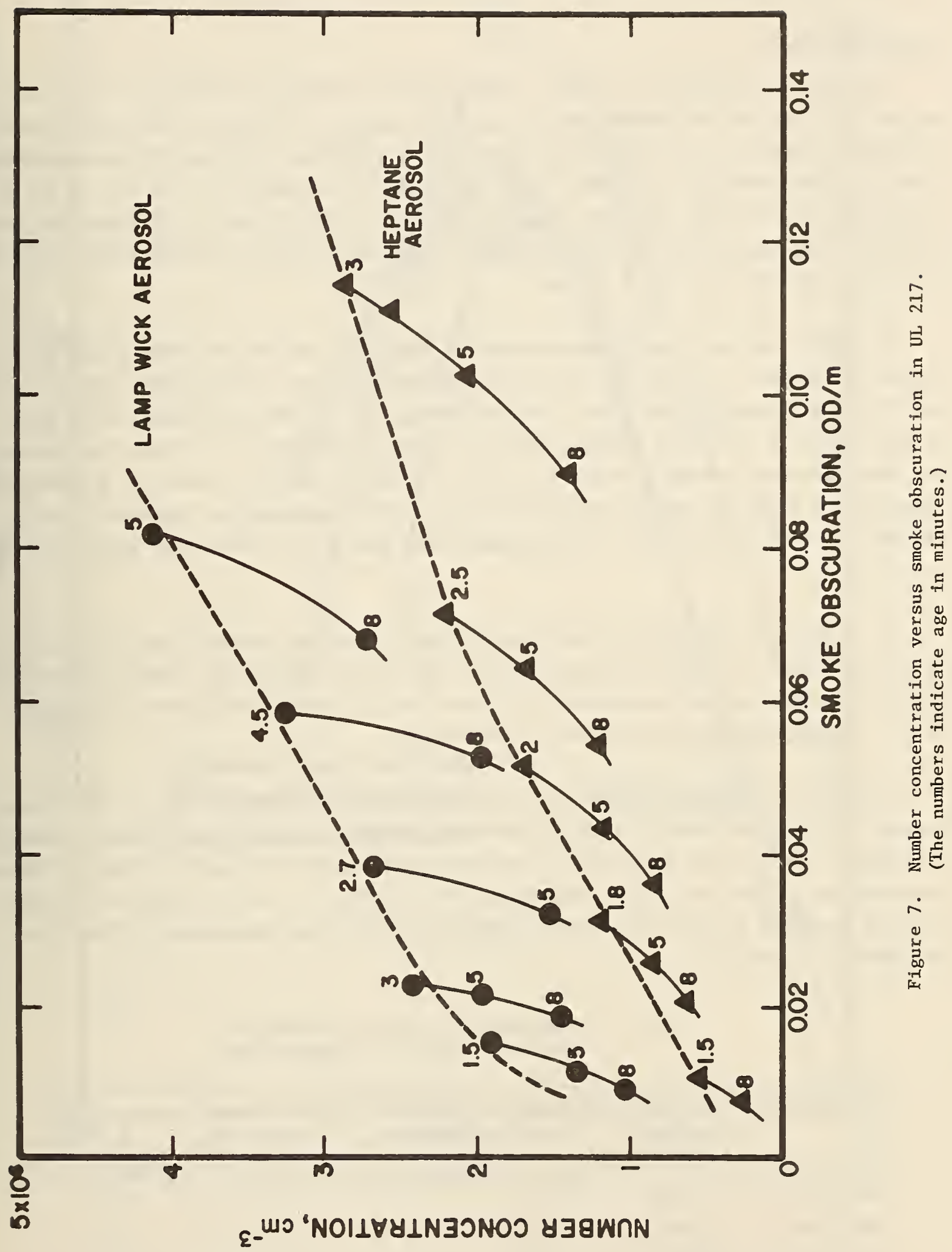


aerosol. This observation and its implication in the use of the UL 217 chamber will be discussed in Section 6.2.

\section{Size Distribution}

The size distribution of aerosols generated under standard conditions for detector evaluation in the UL 217 chamber were measured by the EAA. In figure 8 the results based on three determinations are given for smoke aerosol generated from lamp wick at obscuration levels of $0.066 \mathrm{OD} / \mathrm{m}$ and $0.015 \mathrm{oD} / \mathrm{m}$, which approximately correspond to the minimum $(0.06 \mathrm{OD} / \mathrm{m})$ and maximum $(0.006 \mathrm{OD} / \mathrm{m})$ allowable detector sensitivity used by the UL 217 method for approval purposes. The ages of the lamp wick aerosols were 9 and 4 minutes, respectively, while the age of the heptane smoke was 6 minutes.

In table 2 the key physical parameters for lamp wick and heptane smoke in the UL 217 chamber are given. For lamp wick smoke, the parameters given represent approximately both the allowable minimum and maximum light obscuration levels. Two significant differences between lamp wick smoke and heptane smoke are apparent from table 2. First, heptane smoke has about twice the optical density per meter compared to lamp wick smoke for a given mass concentration based on particle mass monitor and filter measurements. Secondly, the size distribution $\left(\sigma_{g}\right)$ is narrower for the heptane smoke than for the lamp wick smoke (also in fig. 8).

It is apparent from table 2 that optical density and mass concentration for the two lamp wick smokes are linearly related but that the optical density and number concentration are not. As will be explained more fully later, this is because coagulation affects the number concentration but not the mass concentration.

The relative agreement between the mass concentration as measured by the PMM (Particle Mass Monitor) and as derived from EAA (Electrical Aerosol Analyzer) measurements (assuming unit density for the smoke) is typical for many measurements. The ratio of the EAA number concentration to that of the CNM (Condensation Nuclei Monitor) for the lamp wick smokes is somewhat less than 2, which is a typical number for many other measurements as will be discussed in Section 6.

Table 2. Measured and Derived Parameters of Smokes in the UL 217 Chamber Test

\begin{tabular}{lcrrrrrr}
\hline Instrument & $\begin{array}{c}\text { UL } 217 \\
\text { Obscuration } \\
\text { OD/m }\end{array}$ & $\begin{array}{c}\text { PMM } \\
\text { Mass }\end{array}$ & $\begin{array}{c}\text { Concentration } \\
\mathrm{mg} / \mathrm{m}^{3}\end{array}$ & $\begin{array}{c}\text { EAA } \\
\text { Number } \\
10^{6}\end{array}$ & $\begin{array}{c}\text { CNM } \\
\mathrm{cm}^{-3}\end{array}$ & $\begin{array}{c}\overline{\mathrm{D}}_{\mathrm{g}} \\
\mu \mathrm{m}\end{array}$ & $\mathrm{g}$ \\
\hline Lamp wick & 0.066 & 42 & 21 & 3.4 & 2.5 & 0.14 & 1.7 \\
Lamp wick & 0.015 & 10 & 6 & 1.4 & 1.0 & 0.12 & 1.6 \\
Heptane & 0.017 & $5 *$ & 5 & 0.9 & 0.3 & 0.16 & 1.5 \\
\hline K
\end{tabular}

Filter-Collection Method 


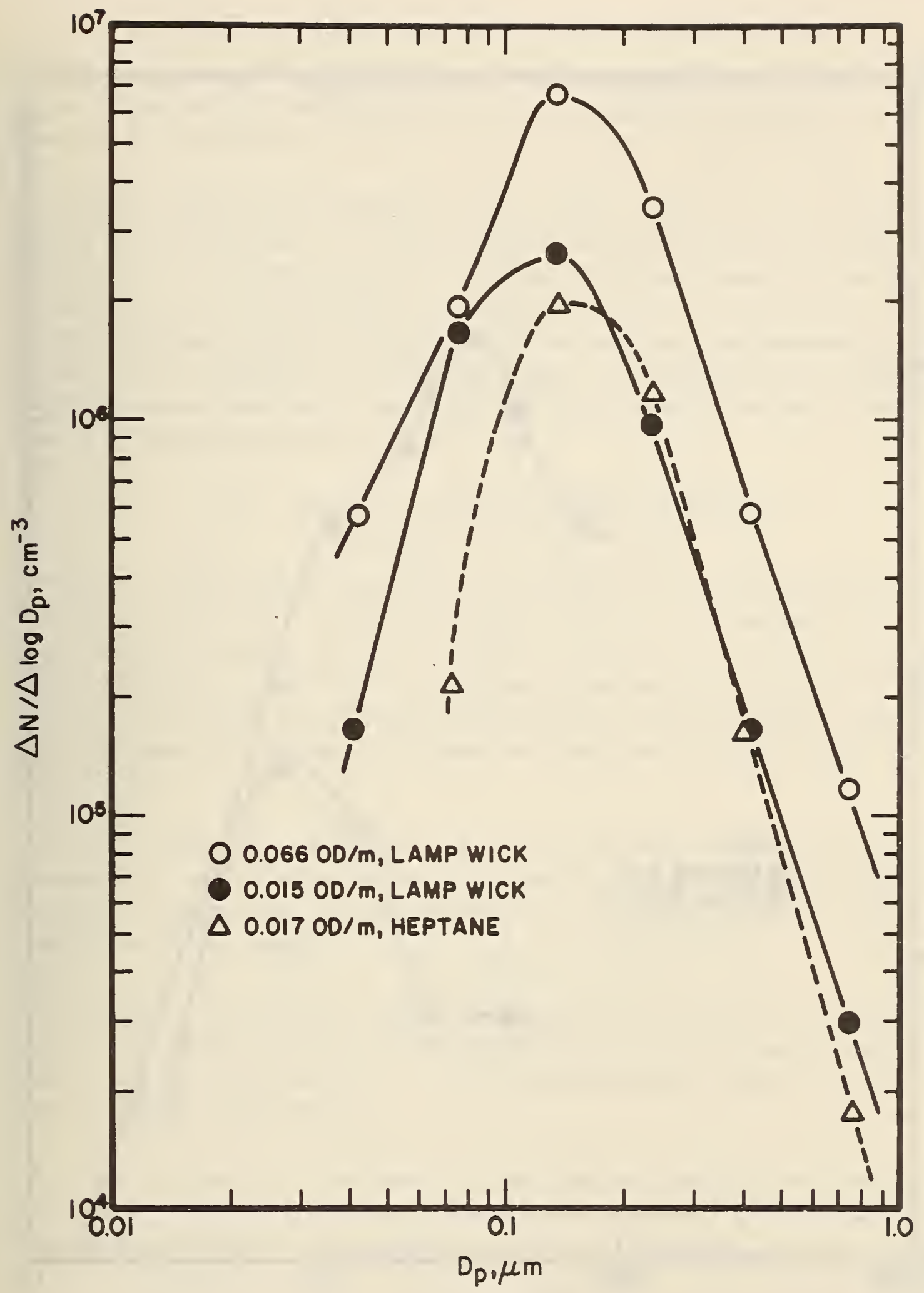

Figure 8. Particle size distribution for lamp wick and heptane smokes. 


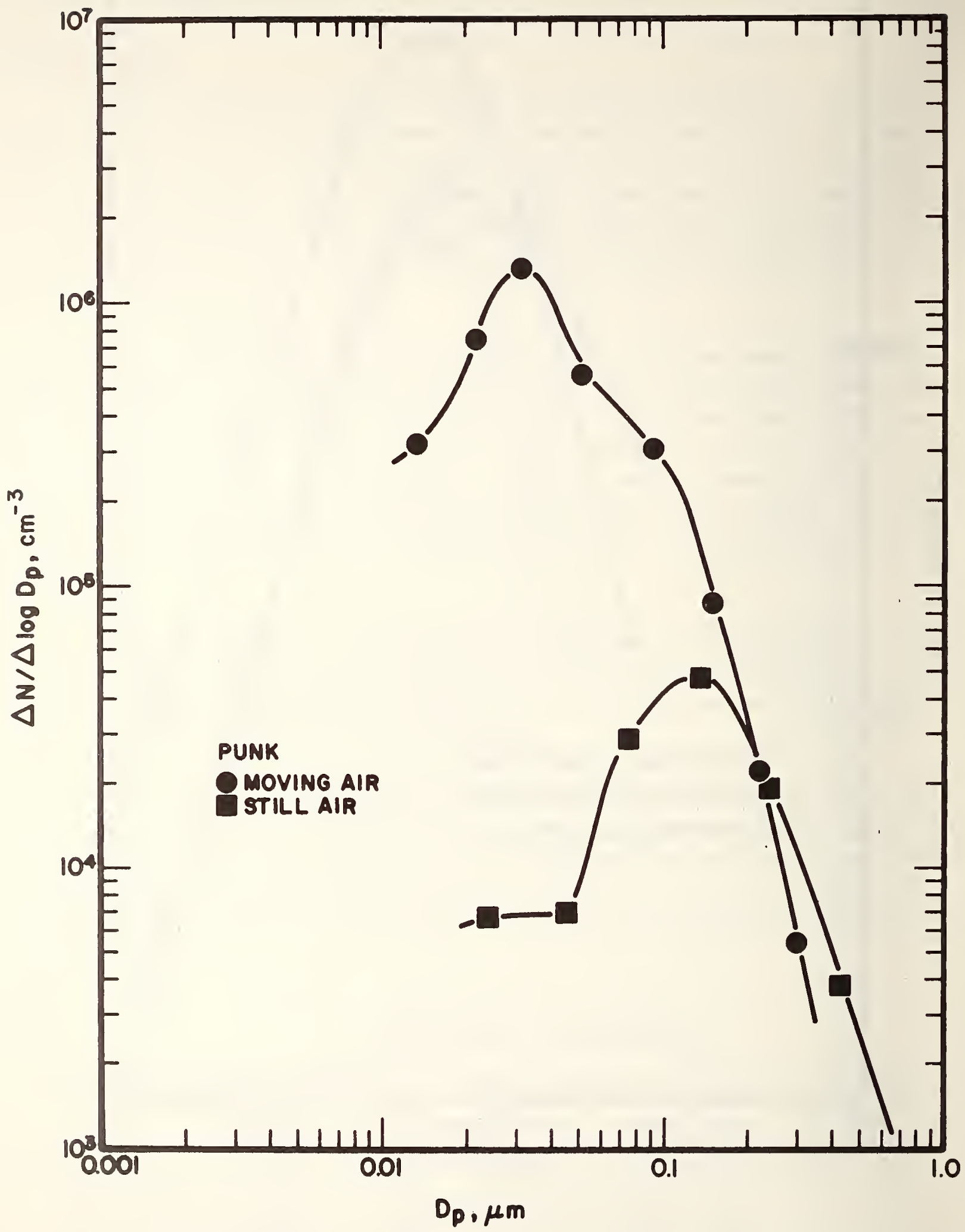

Figure 9. Effect of air movement $(2 \mathrm{~m} / \mathrm{s})$ on particle size. 


\subsection{The Effect of Pyrolysis Conditions on Particle Sizes}

The temperature and ambient airflow above the material undergoing pyrolysis have strong effects on the particle size distribution of the resultant smoke aerosols. Such effects were examined using punk and $\alpha$-cellulose disc in the $\left(1.8 \mathrm{~m}^{3}\right)$ aerosol chamber.

Figure 9 shows two size distribution curves. One represents the aerosol from a smoldering punk stick (glowing but not flaming) held in a vertical position with the hot tip at the top in still air. The other curve shows a similar burning mode except that the punk stick was exposed to an air stream moving at a velocity of 2 to $2.5 \mathrm{~m} / \mathrm{s}$. There is a considerable difference between the two size distributions. The peak size is approximately 4 times larger for the still air compared to the moving-air smokes. A calculation based on figure 9 shows that the moving-air smoke was produced at a rate of $10^{9}$ particles per second compared to only $10^{8}$ particles per second for the still air.

\subsection{Effect of Flaming and Non-flaming Exposure on}

Particle Size of $\alpha$-cellulose Smoke

The size distribution of smoke aerosols also depends strongly on whether the material is flaming or smoldering. In this experiment an $\alpha$-cellulose disc was placed on top of a metal surface maintained at $500^{\circ} \mathrm{C}$ and in another, the disc was ignited by a very small premixed pilot flame. Figure 10 shows the size distribution of the two aerosols sampled from the $1.8 \mathrm{~m}^{3}$ chamber after an aging and mixing period of about 5 minutes. Aerosol concentration peaked at less than $0.01 \mu \mathrm{m}$ under the flaming mode compared to $0.075 \mu \mathrm{m}$ under the smoldering mode.

Figure 11 shows an interesting mixture of aerosols generated under two distinct modes of combustion. An $\alpha$-cellulose disc was being heated at a rate of about $100^{\circ} \mathrm{C} / \mathrm{min}$ from room temperature to $600^{\circ} \mathrm{C}$. Self-ignition occurred when the partially pyrolyzed specimen reached a temperature of about $550^{\circ} \mathrm{C}$.

The peaks in the size-distribution curves indicate the existence of a mixture of the two aerosols; one characteristic of smoldering exposure, which resulted in a peak at about $0.075 \mu \mathrm{m}$. Another is characteristic of the flaming mode which generated much smaller particles with peak at about $0.024 \mu \mathrm{m}$.

As the smoke aged, the concentration of most sizes decreased with the smaller particles decreasing at a much faster rate than the larger size particles. After 30 minutes the peak has shifted to $0.075 \mu \mathrm{m}$. 


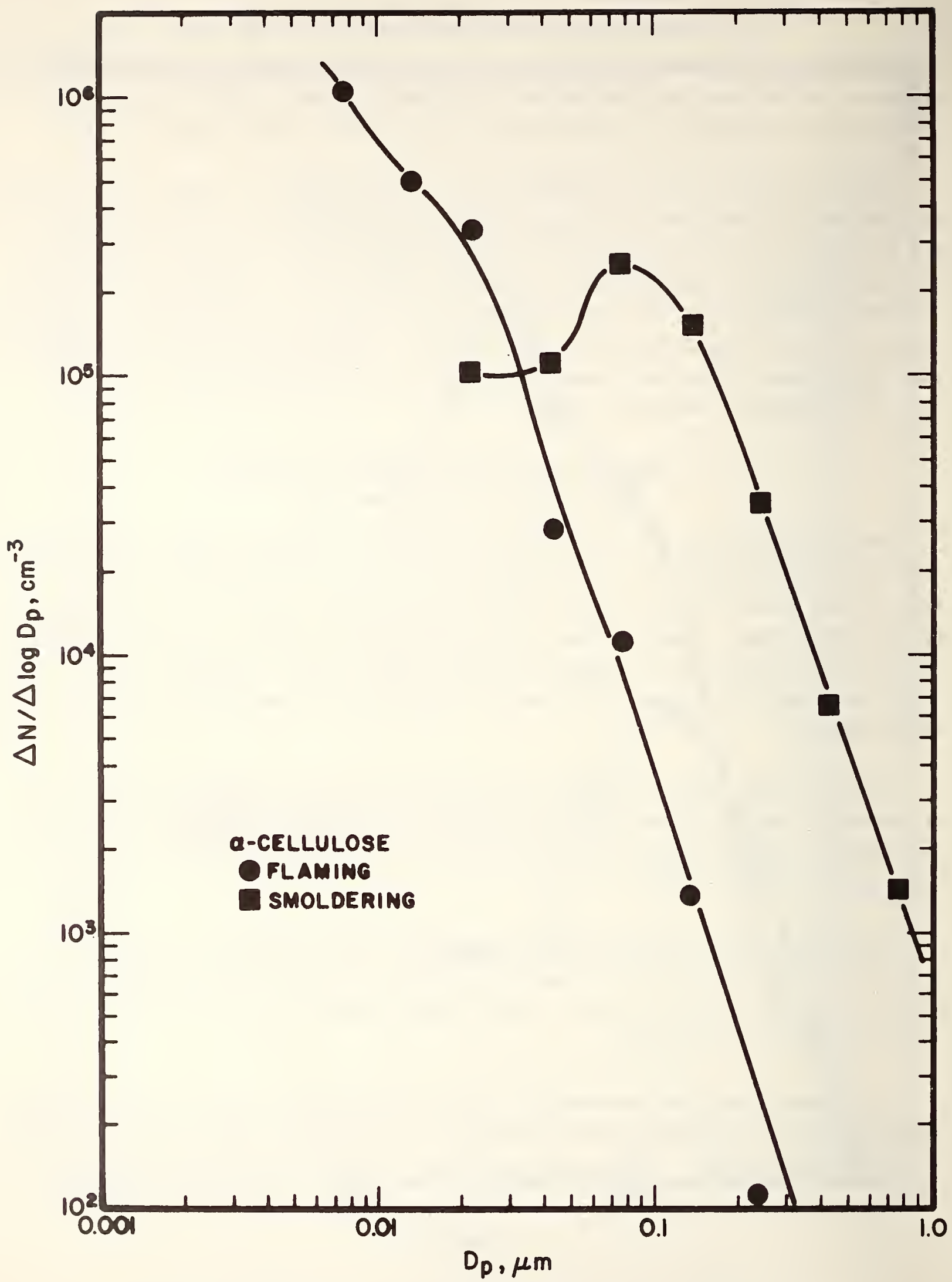

Figure 10. Smoke from $\alpha$-cellulose under flaming and non-flaming exposure conditions. 


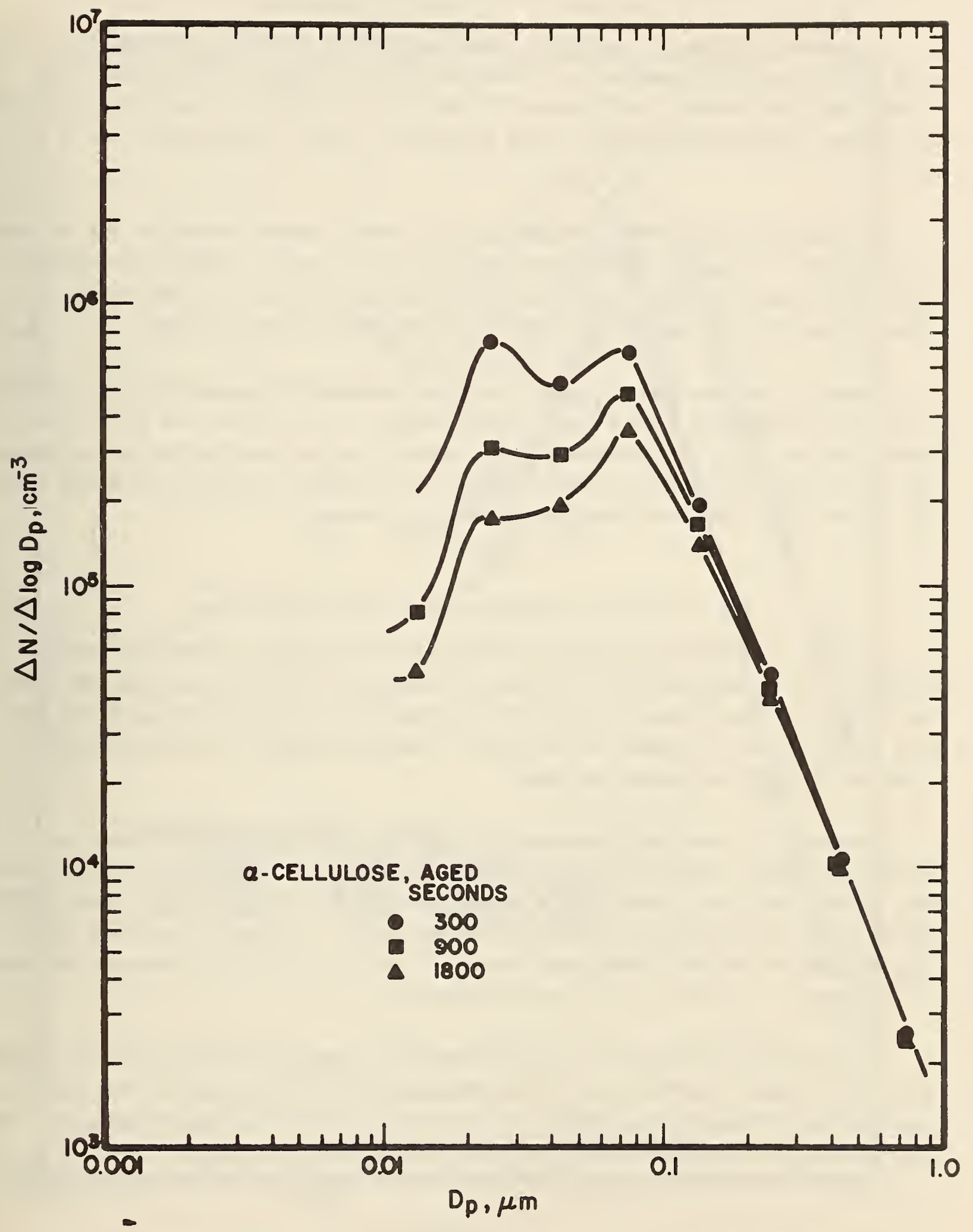

Figure 11. Aging of aerosol from source which progresses from smoldering to flaming. 


\subsection{Influence of Pyrolysis Air Temperatures}

To separate the effect of pyrolysis temperature and the influence of coagulation in the early phase of particle formation, an $\alpha$-cellulose disc was exposed to high-velocity air streams which were heated to $395^{\circ} \mathrm{C}$ and $485^{\circ} \mathrm{C}$. Hot air at a velocity of about $0.6 \mathrm{~m} / \mathrm{s}$ flowing thru a 13-mm diameter tube impinged on the sample disc ( $8.6 \mathrm{mg}$ ) located in the end of the tube.

The resultant aerosol was discharged into the aerosol chamber, allowed to age and analyzed by the EAA. Because of the high airflow rate at the generating source, particle size growth due to aging was effectively frozen until the aerosol began to accumulate in the chamber. The time for complete generation of the aerosols was about 1 minute.

Figure 12 shows two sets of curves. Each set represents the particle size distribution of the aerosol generated under a given air temperature. Peak particle size for the aerosol formed under the $395^{\circ} \mathrm{C}$ condition was $0.13 \mu \mathrm{m}$; whereas, the peak size for the aerosol generated under the high temperature of $485^{\circ} \mathrm{C}$ was $0.075 \mu \mathrm{m}$. Because of aging the peak size gradually shifted to $0.13 \mu \mathrm{m}$ after about 30 minutes in the chamber.

\subsection{Influence of Aging on Particle Size Distribution}

Particle coagulation (aging) due to Brownian collisions plays an important role in changing the size distribution of an aerosol. Coagulation is said to occur when two particles collide and form a single particle whose volume is the sum of the volumes of the original two particles. The number of particles is thereby decreased by one while the total volume of the particles remains the same.

The results of some aging experiments on punk and $\alpha$-cellulose smoke are shown in figures 11-13 where size distribution measurements were made at various times. The coagulation process results in a large drop in number concentration and a noticeable change in particle size distribution for $\alpha$-cellulose and punk smoke. In figure 12 the total number concentration for the $395^{\circ} \mathrm{C}$ smoke drops from $2.0 \times 10^{6}$ to $1.3 \times 10^{6}$ in 10 minutes with most of the change taking place for the small particle sizes.

The aging data in figure 13 is quite extreme with a variation of two orders of magnitude in the total number of particles per cubic centimeter over a 16-hour period. The rate of particle loss by coagulation is shown by the figure to be faster at high concentration. This is consistent with coagulation theory and will be discussed in Section 6.4 . 


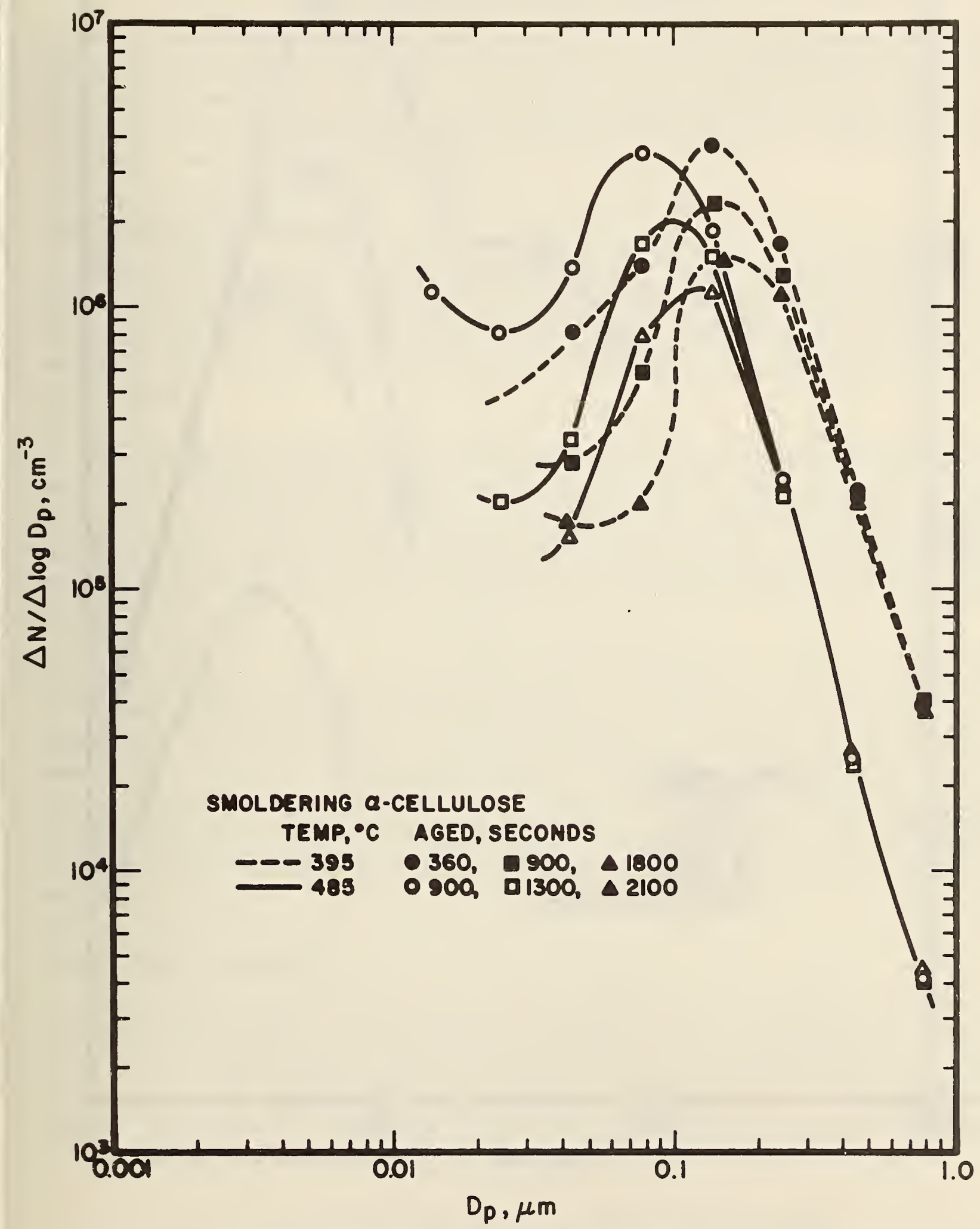

Figure 12. Aging of aerosols generated at two temperatures. 


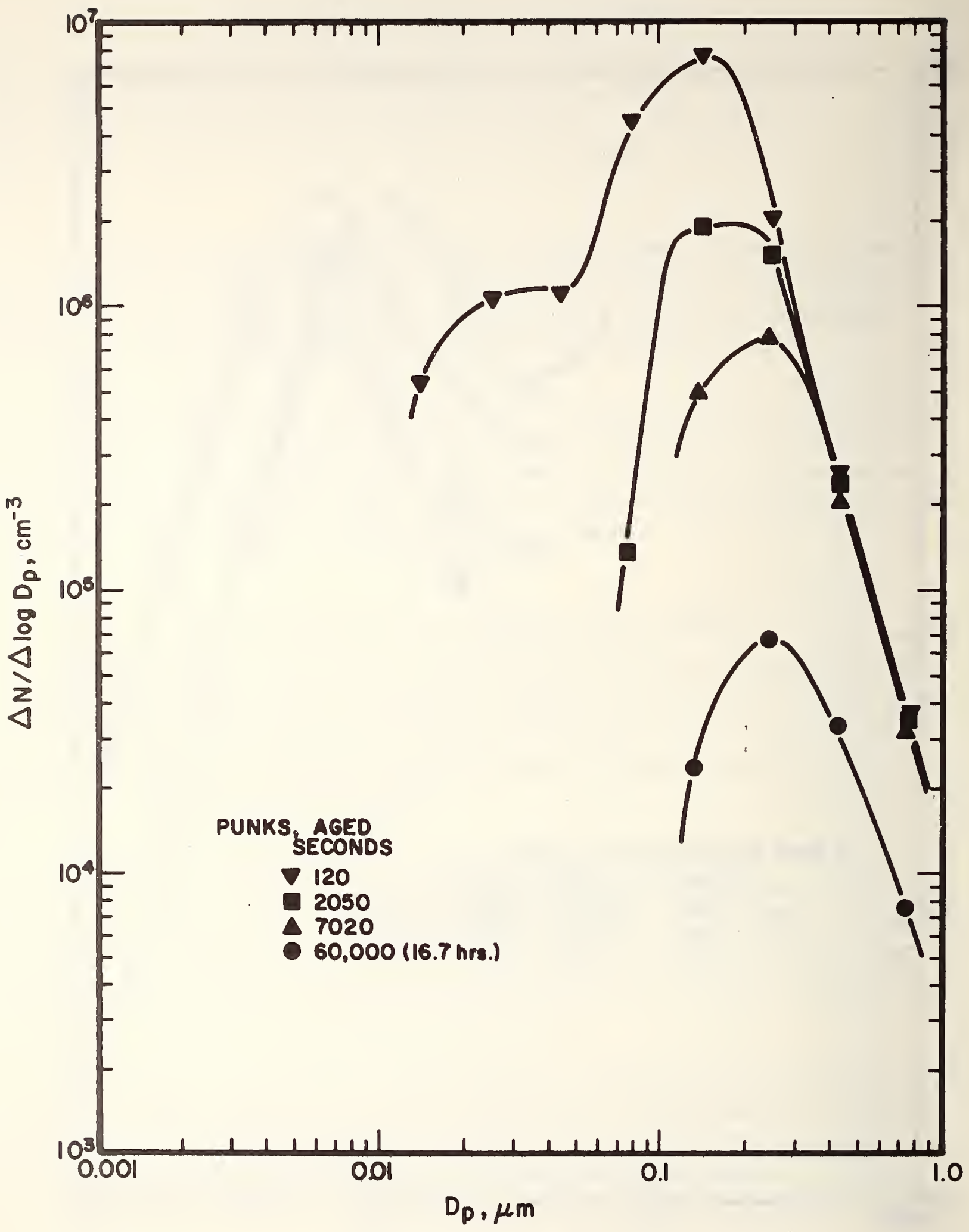

Figure 13. Aging of punk aerosol up to 16 hours. 


\section{DISCUSSION}

\subsection{Comparison of Measurement Methods}

Since the instruments used in this work were based on different measurement principles with different ranges, sensitivities and calibrations, it is not surprising that data from different instruments do not coincide. The results were compared to determine the range of correlation so that measurement by a single instrument may be sufficient in predicting the response from another method of measurement.

\section{Mass Concentration Measurement}

The performance of the mass monitor was compared with that of the filter-collection method for some punk smokes. The mass monitor results were generally about $10 \%$ lower than the filter results. The data were taken from 10 sets of measurements during a one-month perlod for aerosols with peak sizes between 0.05 and $0.12 \mu \mathrm{m}$ in the concentration ranges of 10 to $17 \mathrm{mg} / \mathrm{m}^{3}$.

The discrepancy in results may be attributed to poor collection effeciency of the mass monitor. Varying collection efficiency has also been observed by others for different types of aerosols [24]. The mass monitor was not used in determining the concentration of heptanegenerated smoke because of poor collection efficiency. In subsequent work, the mass monitor was calibrated for the speciffc type of smoke based on the filter-collection method to minimize error.

In estimating the relative consistency of results obtained by the quartz mass monitor and the EAA instrument, the data on size-distribution from the EAA were converted to total mass assuming spherical particles and a density of unity for all sizes in the aerosol. The average ratio between the mass measurement obtained by the quartz monitor and mass based on size measurement by EAA was $1.5 \pm 0.3$ (avg. \pm std. dev.) for over 20 separate punk aerosols. The ratio appeared to increase with the peak size and age of the aerosols. This is consistent with recent data on polydisperse aerosols where it was found that the ratio also increases with particle size.

\section{Particle Number Measurements}

For a given aerosol, number concentration was measured by both the CNM and by the EAA. Comparison of the results in cases where both instruments were used simultaneously, showed that the EAA registers higher values than the CNM. The ratio between EAA and CNM was $2.0 \pm$ 0.3 (avg. \pm std. dev.) for 15 punk and $\alpha$-cellulose aerosols measured in the concentration range of $10^{4}$ to $10^{6} \mathrm{~cm}^{-3}$. This discrepancy is in the same direction and similar in magnitude to that found by Liu, et a1. [21]. 


\subsection{UL 217 Detector Evaluation Chamber}

Measurements in the UL 217 standard detector chamber show the relationship of particle number concentration, mass concentration and aging of standard smoke aerosols to light obscuration, the criterion for approval testing. The maximum allowable alarm threshold of $0.06 \mathrm{OD} / \mathrm{m}$ was found to correspond to a mass concentration of $40 \mathrm{mg} / \mathrm{m}^{3}$ for lamp wick and $18 \mathrm{mg} / \mathrm{m}^{3}$ for heptane aerosols. The corresponding number concentration for fresh smokes were about $3.5 \times 10^{6}$ and $1.6 \times 10^{6}$ particles $/ \mathrm{cm}^{3}$ for the aerosols, respectively.

Since detector sensitivity is fundamentally determined by aerosol concentration, particle size and in certain cases, refractive index, rather than by light obscuration, a detector response (triggering threshold) to lamp wick smoke is unlikely to be identical to that of another smoke, say, heptane smoke, with the same obscuration. For this reason, the UL maximum alarm threshold for the black smoke test has been established at $0.14 \mathrm{oD} / \mathrm{m}(10 \% / \mathrm{ft})$ instead of $0.06 \mathrm{oD} / \mathrm{m}$ used for the grey smoke.

Specific deficiencies of the UL 217 test method include the repeatability in aerosol generation and the effect of aging in the chamber as shown in figure 6 . The variation in generation rate is on the order of $\pm 20 \%$. The aging effect is also illustrated in figure 7 . Since the residence time (aging duration) of the test smokes varies, depending on the triggering level and entrance resistance of the detector, the difference between low and high obscuration smokes depends not only on concentration but also on the size distribution of the aerosols. Therefore, measurements of other variables in addition to obscuration are needed for an adequate measure of detector sensitivity.

\subsection{Aerosol Generation Modes}

The mode of combustion was shown to have a large effect on the size distribution of the resultant aerosol. For $\alpha$-cellulose, the flaming mode produces much smaller particles $\left(\bar{D}_{g}=0.01 \mu \mathrm{m}\right)$ than the smoldering mode $\left(\bar{D}_{g}=0.07\right)$. Even under smoldering conditions, the size distribution is affected by the flow conditions and the temperature. Both an increase in temperature and an increase in flow velocity result in a decrease in particle size though the relative importance of the two effects was not quantitatively studied. An experiment (Section 5.4.), in which coagulation was minimized by high flow velocity, showed a noticeable reduction in particle size with increased temperature. An increase in temperature apparently causes smaller particle size through more complete combustion while an increase in velocity is believed to decrease the time for particle growth by coagulation.

\subsection{Aerosol Aging and Coagulation Losses}

The effect of aging, which seems to show a disproportionate loss of smaller particles with little gain in larger particles, is amply illustrated in figures 11-13. The fact that it takes a thousand $0.1 \mu \mathrm{m}$ particles to form a single $1.0 \mu \mathrm{m}$ particle is a qualitative 
explanation of the aging curves; but to determine how well this data fits the overall coagulation theory, the average coagulation coefficient for each smoke was calculated.

The fundamental quantity for coagulation is the coagulation coefficient, $\Gamma$, which is defined by:

$$
\frac{\mathrm{dN}}{\mathrm{dt}}=-\Gamma \mathrm{N}^{2}
$$

The fact that the loss rate is proportional to the square of the number concentration explains the observation made in Section 5.5. that the rate of particle loss is much faster at higher concentrations. The calculation of the coagulation coefficient was based on the integrated version of the above equation:

$$
\frac{1}{N}-\frac{1}{N_{0}}=\Gamma t
$$

As defined above, $\Gamma$ is an average coagulation coefficient for a given aerosol, through $\Gamma$ in reality is particle size dependent. For the punk smoke data reported in figure 13 plus 2 sets of data reported by Mulholland et al. [10], $\Gamma$ was found to be in the range between 3.9 and $4.6 \times 10^{-10} \mathrm{~cm}^{3} / \mathrm{s}$ with peak diameter on the order of $0.15 \mu \mathrm{m}$.

For flaming $\alpha$-cellulose, $\Gamma$ was found to be between 10 and $19 \times 10^{-10} \mathrm{~cm}^{3} / \mathrm{s}$ with peak diameter around $0.05 \mu \mathrm{m}$. These values are of the same order of magnitude as the theoretical values reported by Zebel [28]. The fact that the smaller particle size has the larger $\Gamma$ is also consistent with the work reported by Zebel [28].

\subsection{Universal Size Distribution}

A representative sample of all the data displayed in the previous figures has been plotted in terms of reduced variables $\psi$ and $n$ in figure 14 . The number distribution is reduced by the total number of particles in the size distribution, $N(t)$, and the diameter is reduced by a quantity related to the average diameter for the size distribution, $(\mathrm{V} / \mathrm{N})^{1 / 3}$ for that particular smoke. Thus:

$$
\begin{aligned}
& \psi=\frac{\Delta N}{\Delta \log D N(t)} \\
& n=D(N(t) / V)^{1 / 3} .
\end{aligned}
$$

The data includes fresh smoke as well as aged smoke, smoke generated in both the flaming and smoldering modes, whitish smoke and black sooty heptane smoke, and smoke generated under 


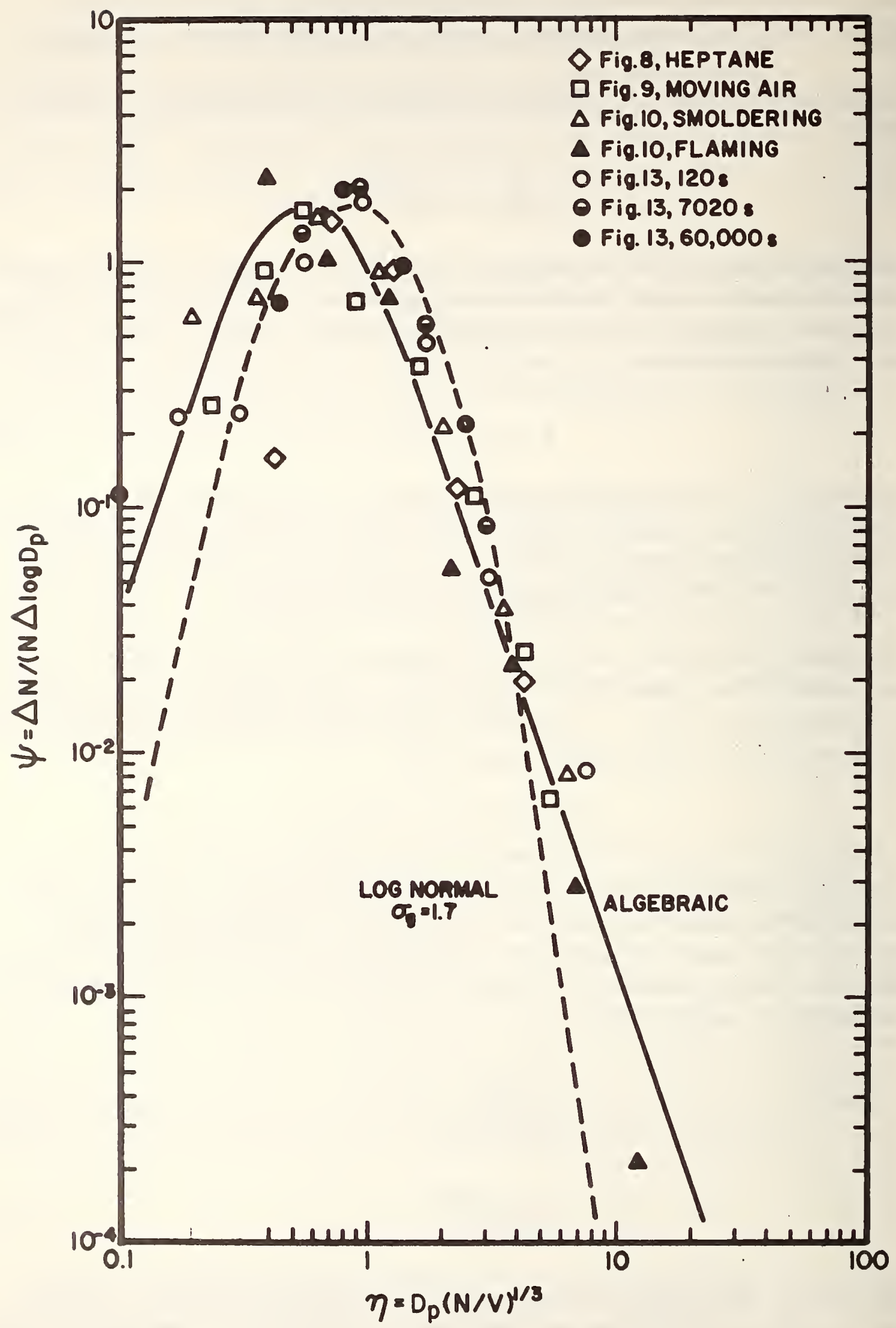

Figure 14. Representative size distributions in terms of reduced variables. 
different airflow conditions. The numerical variation in size distribution data is greatly reduced by using the reduced variables. Based on the reduced varlable, the ranges, for the peak size and peak concentration are $0.5-1.0$ and $1.4-2.0$ respectively for the data in figure 14 compared to $0.03-0.25, \mu \mathrm{m}$ and $5 \times 10^{4}-8 \times 10^{6} \mathrm{~cm}^{-3}$ respectively for the unreduced data. This is with the exception of flaming $\alpha$-cellulose which does not have a peak. There is a qualitative agreement in the shape of the size distribution for all the data especially for the larger values of $n$. From the data for small $n$, it appears that the heptane smoke has a narrower distribution than the others.

Also shown in figure 14 are the reduced versions of an algebraic size distribution (see equation 6) and a log-normal size distribution (see equation 5).

$$
\begin{aligned}
& \psi=1.38 n^{3}\left(n^{3}+0.2\right)^{-2}, \text { Junge-11ke } \\
& \psi=1.73 \exp ^{-\left[\frac{\ln 1.23 n}{0.744}\right]^{2}}, 10 g \text {-normal with } \sigma=1.7 .
\end{aligned}
$$

It appears that both the algebraic distribution and the $\sigma_{\mathrm{g}}=1.7$ log-normal distribution fits the data. It has been shown by Mulholland, et al. [10] in a coagulation calculation that the reduced algebraic distribution is only weakly affected by aging due to coagulation as is the case experimentally (see aging data in figure 14). This means that the algebraic distribution could be used as a model size distribution not only for a variety of smokes but also for smokes at various stages of aging. It is not known whether the log-normal size distribution also has this property.

The observation that a number of different smokes can be represented by a simple algebraic form could have important practical applications. By measuring two macroscopic properties of a smoke aerosol, the number and volume concentration, and by using the algebraic form, one can obtain a good estimate of the size distribution, $\Delta N / \Delta \log D$. The method for doing this is outlined below. The practical advantage is that it is easier and less expensive in terms of instrumentation to measure the concentration of an aerosol with a nuclei counter and the mass concentration by a filter method than to measure the full size distribution with an EAA or with an electron microscope. The danger, of course, is that the smoke, for any of a number of reasons, might not follow this distribution.

The procedure for obtaining the physical size distribution from the reduced size distribution is best explained by an example. Assume that the number and volume concentration have been measured and $N=8.2 \times 10^{5} \mathrm{~cm}^{-3}$ and $\mathrm{V}=137 \mu \mathrm{m}^{3} / \mathrm{cm}^{3}$. From equations (9), (10), and (11) one finds that

$$
\frac{\Delta \mathrm{N}}{\Delta \log \mathrm{D}_{\mathrm{p}}}=\frac{1.38 \mathrm{~V} \mathrm{D}^{3}}{\left(\mathrm{D}^{3}+\frac{0.2 \mathrm{~V}}{\mathrm{~N}}\right)^{2}}
$$




$$
\frac{\Delta \mathrm{N}}{\Delta \log \mathrm{D}_{\mathrm{p}}}=\frac{1.9 \times 10^{2} \frac{\mu \mathrm{m}^{3}}{\mathrm{~cm}^{3}} \mathrm{D}^{3}}{\left(\mathrm{D}^{3}+3.3 \times 10^{-5} \mathrm{\mu m}^{3}\right)^{2}}
$$

\section{SUMMARY AND CONCLUSIONS}

Commercial instruments including the electrical aerosol analyzer, condensation nuclei monitor, optical particle counter, piezoelectric mass monitor and filter collection method were found to have sufficient precision and sensitivity for determining the size distribution, particle number concentration, and mass concentration of aerosols in the alarm-triggering range of smoke detectors. More confidence is placed on the relative values rather than the absolute values of the data. Because of the difference in operating principle and sensitivity ranges of the instruments, experimentally determined ratios were used to correlate results from different measurement methods. These ratios are: $\frac{N(E A A)}{N(C N M)} \sim 2, \frac{M(P M M)}{M(E A A)} \sim 1.5$ where $N=$ number concentration and $\mathrm{M}=$ mass concentration.

The maximum allowable alarm threshold for detector approval under UL $217,0.06$ oD/m $(4 \% / \mathrm{ft})$, was found to correspond to a mass concentration of $40 \mathrm{mg} / \mathrm{m}^{3}$ and a number concentration of $4 \times 10^{6} \mathrm{~cm}^{-3}$ with peak at about $0.15 \mu \mathrm{m}$ for the standard lamp wick aerosol.

The UL 217 detector evaluation chamber, based only on the light attenuation (obscuration) property of the smoke, has limitations in providing the basis for judging detectors in terms of sensitivity. Some of the limitations are:

1. Aerosols having identical light attenuation values in the chamber could show considerable difference in concentration or size distribution including $\bar{D}_{g}$ and $\sigma_{g}$ and have a different effect on detector response.

2. Size distribution of the smoke changes as the smoke concentration increases in the UL 217 chamber. The peak size increases on the order of $20-40 \%$ as obscuration changes from 0.015 to $0.06 \mathrm{oD} / \mathrm{m}$.

The deficlencles can be removed by using a highly repeatable steady-state aerosol source such as an aerosol generator.

It was found that many factors affect the size distribution of smoke aerosols: 
1. The peak particle size from a cellulosic material under smoldering condition $(\sim 0.075 \mu \mathrm{m})$ was several times larger than that under flaming condition $(\sim 0.013 \mu \mathrm{m})$.

2. The peak particle size from $\alpha$-cellulose decreased by a factor of about two when its exposure temperature was increased by about $100^{\circ} \mathrm{C}$ from $395^{\circ} \mathrm{C}$.

3. The peak particle size from smoldering punk decreased by a factor of about four when the airflow velocity was increased from near 0 to $2 \mathrm{~m} / \mathrm{s}$.

4. The size distribution for heptane smoke $\left(\sigma_{g}=1.5\right)$ was narrower than for cellulosic smoke $\left(\sigma_{g}=1.7\right)$.

The coagulation coefficient for punk smoke was found to be about $4.3 \times 10^{-10} \mathrm{~cm}^{3} / \mathrm{s}$. The number concentration of punk smoke with the above coefficient will change $\mathrm{from} 1.0 \mathrm{x}$ $10^{7} \mathrm{~cm}^{-3}$ to $0.44 \times 10^{7} \mathrm{~cm}^{-3}$ in 5 minutes resulting in a $30 \%$ increase in peak size.

While there was considerable variation in the peak size and concentration of the various smokes generated, there was a general similarity in the shape of the size distribution that allowed most of the data to be reduced to a single curve. It was found that a simple algebraic function fits the data quite well for both fresh as well as aged smoke. This universal distribution is of basic significance for smoke aerosols and also could be of greater practical use in data correlation and smoke detector testing.

The largest particle size measured in this study was $1 \mu \mathrm{m}$. There is a need for size distribution measurements up to $5 \mu \mathrm{m}$ as well as more accurate measurements over the range $0.3 \mu \mathrm{m}$ to $1 \mu \mathrm{m}$. Such information will be useful in better defining the universal distribution as well as providing needed information for predicting the response of light-scattering type detectors.

Similar types of measurements to those given in this study, if extended to other materials such as plastic fabrics and elastomers as well as to ambient aerosols, would further delineate the problem of false alarms. 


\section{REFERENCES}

[1] McGuire, J. H. and Ruscoe, B, E., Fire Study No. 9, National Research Council, Canada (1962).

[2] Harpe, S. W., Waterman, T. E. and Christian, W. J., Detector Sensitivity and Siting Requirement for Dwellings, Phase 2 Nat. Bur. Stand. (U.S.), NBS-GCR 77-82 (1977).

[3] Bright, Richard G., Nat. Bur. Stand. (U.S.) (1977), private communication.

[4] Standard for Single and Multiple Stations Smoke Detectors UL 217, Underwriters' Laboratories, Inc. (Jan. 1976).

[5] Bukowski, Richard W. and Bright, Richard G., Results of Ful1-Scale Fire Tests with Photoelectric Smoke Detectors, Nat. Bur. Stand. (U.S.), NBSIR 75-700 (1975).

[6] Hesyestad, G., Escape Potential from Apartments Protected by Fire Detectors in High Rise Building, Factory Mutual Research, FMRC No. 21017 (1974).

[7] Fry, J. F. and Eveleigh, C., The Behavior of Automatic Fire Detection Systems, Fire Research Note 810, British Fire Research Station, Borehamwood (1970).

[8] Mulholland, George W. and Liu, B. Y. H., Smoke Detector Responses, to be published.

[9] Cadle, Richard D., The Measurement of Airborne Particles, John Wiley \& Sons, New York (1975).

[10] Mulholland, George W., Lee, T. G. and Baum, H., The Coagulation of Aerosols with Broad Initial Size Distribution, J. of Colloid Interface Sci, to be published. .

[11] Liu, Benjamin Y., Editor, Fine Particles - Aerosol Generation, Measurement, Sampling and Analysis, Acacemic Press, Inc. (1976).

[12] Cassatt, W. A., Maddock, R. S., Editors, Aerosol Measurements, Nat. Bur. Stand. (U.S.), Spec. Publ. 412, 193 pages (Oct. 1974).

[13] Whitby, K. T. and Clark, W. E., Tellus, Vol. 18, 573 (1966).

[14] Liu, B. Y. H. and PuI, D. Y. D., On the Performance of the Electrical Aerosol Analyzer, J. Aerosol Sci., Vo1. 6, 24 (1975).

[15] Liu, B. Y. H., Berglund, R. N. and Argawa1, J. K., Atm. Env., Vol. 8, 717 (1974).

[16] Whitby, K. T., Electrical Measurement of Aerosols, Fine Particles - Aerosol Generation, Measurement, Sampling and Analysis, B. Y. Liu, Editor, Academic Press, 581 (1976).

[17] Willeke, Klaus and Liu, B. Y. H., Single Particle Optical Counter, Fine Particles Aerosol Generation, Measurement, Sampling and Analysis, B. Y. Liu, Editor, Academic Press, 697 (1976).

[18] Instruction Manual Particle Counter Model 200-5, Techecology, Inc. (Met One) (1974).

[19] Cooke, D. D. and Kerker, M., Response Calculation for Light Scattering Aerosol Particle Counters, Applied Optics, Vol. 14, 734 (1975). 
[20] Manual for Condensation Nuclei Monitor, Model Rich 100 (1971), Environmental One Corp., Schenectady, New York.

[21] Liu, B. Y. H. and Pui, D. Y. H., A Submicron Aerosol Standard and the Primary Absolute Calibration of the Condensation Nuclei Counter, J. of Colloid Interface Sci., Vol. 47, 155 (1974).

[22] Instruction Manual, Particle Mass Monitor Mode1 3200, Thermo-Systems, Inc. (1975).

[23] Olin, J. G. and Sem, G. J., Piezoelectric Microbanance for Monitoring the Mass Concentration of Suspended Particles, Atmospheric Environment, Vol. 5, 653 (1971).

[24] Lundgren, D. A., Aerosol Mass Measurement Using Piezoelectric Crystal Sensors, Fine Particles - Aerosol Generation, Measurement, Sampling and Analysis, B. Y. H. Liu, Editor, Academic Press, 485 (1976).

[25] Liu, B. Y. H. and Lee, K. W., Efficiency of Membrane and Nuclepore Filters for Submicron Aerosols, Env. Sc1, \& Tech., Vol. 10, 345 (1976).

[26] Smoke Actuated Detectors for Automatic Fire Alarm Systems, Approval Standard, Factory Mutua1 Research Corp. Norwood, Mass., Class No. 3230-3250 (1973).

[27] Kerker, M., The Scattering of Light and Electromagnetic Radiation, Academic Press, New York (1969).

[28] Zebe1, G., Coagulation of Aeroso1, Aerosol Science, C. N. Davies, Editor, Academic Press, New York (1966). 


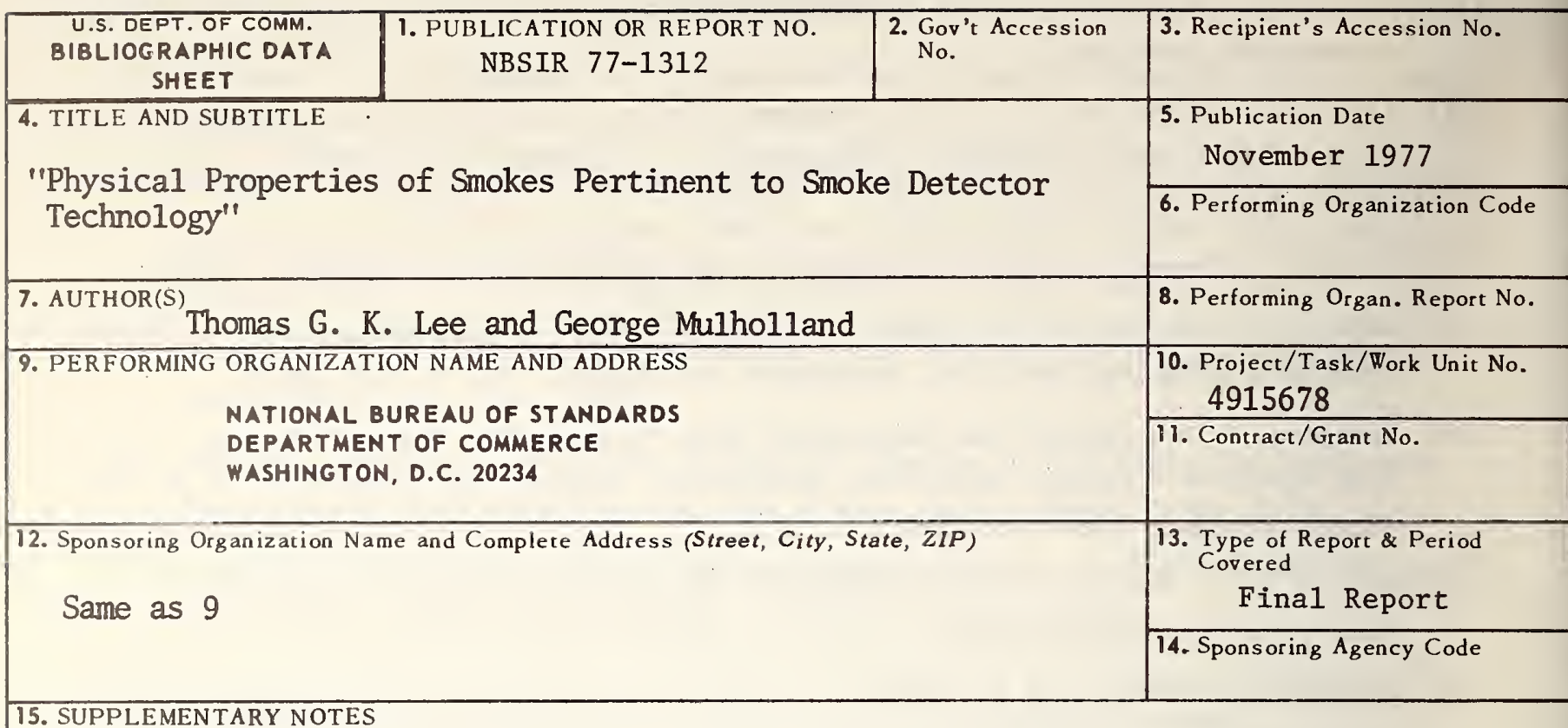

16. ABSTRACT (A 200-word or less factual summary of most significant information. If document includes a significant bibliography or literature survey, mention it here.)

Several commercially available aerosol instruments including the electrical aerosol analyzer, nuclei condensation monitor, quartz mass monitor, and optical particle counter were used to measure particle size distribution of smokes from burning heptane and cellulosic materials. Some limitations of these instruments are discussed. Parameters such as mode of exposure (flaming versus smoldering), pyrolysis temperature, air velocity at smoke emitting site, and aging. were found to have a large effect on the smoke particle size distribution. Mass and number concentrations of smokes from cotton lamp wick as a function of smoke obscuration in the standard UL 217 detector test chamber were determined. The maximum alarm threshold obscuration of $0.06 \mathrm{oD} / \mathrm{m}$ ( $4 \%$ per $\mathrm{ft}$ ), required for detector approval, was found to correspond to lamp wick aerosol mass concentration of $40 \mathrm{mg} / \mathrm{m}^{3}$ and particle concentration of about $4 \times 10^{6} \mathrm{~cm}^{-3}$ with the peak size in the number distribution of about $0.15 \mu \mathrm{m}$. The present UL 217 test method was shown to be affected by smoke coagulation and did not provide a complete measure of sensitivity in smoke detectors. An algebraic model size distribution, with number and mass concentration the only free parameters, was shown to provide a good estimate for all the smoke size distributions measured.

17. KEY WORDS (six to twelve entries; alphabetical order; capitalize only the first letter of the first key word unless a proper name; separated by semicolons)

Aerosol; mass concentration; number concentration; size distribution; smoke; smoke detector; test method; UL 217

\begin{tabular}{|c|c|c|}
\hline $\begin{array}{l}\text { 18. AVAILABILITY } \overline{\square \mathrm{O}} \text { Unlimited } \\
\square \text { For Official Distribution. Do Not Release to NTIS }\end{array}$ & $\begin{array}{l}\text { 19. SECURITY CLASS } \\
\text { (THIS REPURT) } \\
\text { UNCL ASSIFIED }\end{array}$ & $\begin{array}{c}\text { 21. NO. OF PAGES } \\
45\end{array}$ \\
\hline $\begin{array}{l}\square \text { Order From Sup. of Doc., U.S. Government Printing Office } \\
\text { Washington, D.C. } 20402, \text { SD Cat. No. CI3 }\end{array}$ & $\begin{array}{l}\text { 20. SECURITY CLASS } \\
\text { (THIS PAGE) }\end{array}$ & 22. Price \\
\hline $\begin{array}{l}\text { X] Order From National Technical Information Service (NTIS) } \\
\text { Springfield, Virginia } 2215 \mathrm{I}\end{array}$ & UNCLASSIFIED . & $\$ 4: 00$ \\
\hline
\end{tabular}

